\title{
Identification of a 12-Gene Fusaric Acid Biosynthetic Gene Cluster in Fusarium Species Through Comparative and Functional Genomics
}

\author{
Daren W. Brown, ${ }^{1}$ Seung-Ho Lee, ${ }^{2}$ Lee-Han Kim, ${ }^{3}$ Jae-Gee Ryu, ${ }^{3}$ Soohyung Lee, ${ }^{3}$ Yunhee Seo, ${ }^{4}$ \\ Young Ho Kim, ${ }^{4}$ Mark Busman, ${ }^{1}$ Sung-Hwan Yun, ${ }^{5}$ Robert H. Proctor, ${ }^{1}$ and Theresa Lee ${ }^{3}$ \\ ${ }^{1}$ Bacterial Foodborne Pathogens and Mycology Research, USDA-ARS-NCAUR, 1815 N. University St., Peoria, Illinois \\ 61604, U.S.A.; ${ }^{2}$ Ginseng Research Division, National Institute of Horticultural \& Herbal Science, Rural Development \\ Administration, Eumseong 369-873, Republic of Korea; ${ }^{3}$ Microbial Safety Team, National Academy of Agricultural Science, \\ Rural Development Administration, Wanju 565-851, Republic of Korea; ${ }^{4}$ Department of Agricultural Biotechnology and \\ Research Institute for Agriculture and Life Sciences, Seoul National University, Seoul 151-921, Republic of Korea; \\ ${ }^{5}$ Department of Medical Biotechnology, Soonchunhyang University, Asan 336-745, Republic of Korea
}

Submitted 12 September 2014. Accepted 24 October 2014.

In fungi, genes involved in biosynthesis of a secondary metabolite (SM) are often located adjacent to one another in the genome and are coordinately regulated. These SM biosynthetic gene clusters typically encode enzymes, one or more transcription factors, and a transport protein. Fusaric acid is a polyketide-derived SM produced by multiple species of the fungal genus Fusarium. This $\mathrm{SM}$ is of concern because it is toxic to animals and, therefore, is considered a mycotoxin and may contribute to plant pathogenesis. Preliminary descriptions of the fusaric acid (FA) biosynthetic gene $(F U B)$ cluster have been reported in two Fusarium species, the maize pathogen $F$. verticillioides and the rice pathogen $F$. fujikuroi. The cluster consisted of five genes and did not include a transcription factor or transporter gene. Here, analysis of the $F U B$ region in $F$. verticillioides, $F$. fujikuroi, and $F$. oxysporum, a plant pathogen with multiple hosts, indicates the $F U B$ cluster consists of at least 12 genes $(F U B 1$ to $F U B 12)$. Deletion analysis confirmed that nine $F U B$ genes, including two $\mathrm{Zn}(\mathrm{II})_{2} \mathrm{Cys}_{6}$ transcription factor genes, are required for production of wild-type levels of FA. Comparisons of $F U B$ cluster homologs across multiple Fusarium isolates and species revealed insertion of non-FUB genes at one or two locations in some homologs. Although the ability to produce FA contributed to the phytotoxicity of $F$. oxysporum culture extracts, lack of production did not affect virulence of $F$. oxysporum on cactus or $F$. verticillioides on maize seedlings. These findings provide new insights into the genetic and biochemical processes required for FA production.

Collectively, species of the fungal genus Fusarium occur as pathogens or endophytes on a wide variety of economically important plants and can cause opportunistic infections in humans and other animals (Leslie and Summerell 2006). Fu-

*Corresponding authors: D. Brown; E-mail: daren.brown@ars.usda.gov and T. Lee; E-mail: tessyl1@korea.kr

* The $\boldsymbol{e}$-Xtra logo stands for "electronic extra" and indicates that three supplementary figures and five supplementary tables are published online.

This article is in the public domain and not copyrightable. It may be freely reprinted with customary crediting of the source. The American Phytopathological Society, 2015. sarium species also produce over 50 distinct families of secondary metabolites (SM) that vary tremendously in chemical structure and biological activity (Desjardins 2006; Vesonder and Golinski 1989). Some Fusarium SM are pigments, others are plant growth regulators, and some (i.e., fumonisins, trichothecenes, and zearalenone) are among the mycotoxins of greatest concern to food and feed safety. Although some Fusarium SM contribute to pathogenicity, the roles of most in the ecology of Fusarium spp. have not yet been elucidated. Fusaric acid (5butylpicolinic acid [FA]) is a polyketide-derived SM produced by multiple Fusarium species, including Fusarium oxysporum and multiple members of the $F$. fujikuroi species complex (FFSC) (Bacon et al. 1996).

FA is of interest because it has long been associated with plant wilt symptoms caused by infection with some Fusarium species and it exhibits mild levels of toxicity to animals (Bacon et al. 1996; Bouizgarne et al. 2006; D'Alton and Etherton 1984). FA is phytotoxic to cotton (Stipanovic et al. 2011a), its production by $F$. oxysporum $\mathrm{f}$. sp. cubense is correlated with pathogenicity on banana plants ( $\mathrm{Li}$ et al. 2013), and it induces programmed cell death in plants (Jiao et al. 2013; Samadi and Behboodi 2006). Exposure to subtoxic doses of FA can also elicit plant defense responses (Bouizgarne et al. 2006). In addition to a mild toxicity to animals, FA exhibits acanthamoebicidal (Boonman et al. 2012), antioomycete (Son et al. 2008), and antimycobacterial activities (Pan et al. 2011).

Although fungal SM exhibit tremendous diversity in chemical structure and biological activity, their biogenesis exhibits several common themes. In a majority of cases, genes responsible for synthesis of the same SM are coordinately regulated and located adjacent to one another in the genome (Keller et al. 2005; Osbourn 2010). Such biosynthetic gene clusters generally include a key gene encoding an enzyme that catalyzes assembly of the SM chemical scaffold. Typically the enzyme is a polyketide synthase (PKS), non-ribosomal peptide synthase, terpene cyclase, or prenyltransferase. A majority of other cluster genes encode enzymes that catalyze modification of the chemical scaffold, e.g., oxidation, acylation, or cyclization. Most SM biosynthetic gene clusters also encode at least one transcription factor that regulates gene expression within the cluster and a protein that transports the SM out of the cell.

A five-gene FA biosynthetic gene $(F U B)$ cluster was previously identified and characterized in two FFSC species, $F$. ver- 
ticillioides, a causal agent of ear and stalk rot of maize and a frequent endophyte of maize (Brown et al. 2012), and $F$. fujikuroi, the causal agent of "bakanae" disease of rice (Niehaus et al. 2014). Orthologs of the FUB cluster are also present in the other FFSC species $F$. circinatum and $F$. mangiferae as well as in $F$. oxysporum, which is closely related to but not a member of FFSC (Wiemann et al. 2013). The cluster genes were predicted to encode a PKS $(F U B 1)$, a hypothetical protein of unknown function $(F U B 2)$, an amino acid kinase (FUB3), a hydrolase (FUB4), and an acyltransferase (FUB5). Notably absent from the $F U B$ cluster were genes encoding a transcription factor or a transporter. In $F$. verticillioides and $F$. fujikuroi, the five $F U B$ genes were coregulated; i.e., they exhibited similar patterns of expression (Brown et al. 2012; Niehaus et al. 2014). Deletion of FUB1 in both $F$. verticillioides and $F$. fujikuroi abolished FA production (Brown et al. 2012; Niehaus et al. 2014). In an analysis of F. fujikuroi, FUB4 deletion abolished FA production, FUB3 and FUB5 deletion reduced production by 20 to $40 \%$, and $F U B 2$ deletion had no effect on production (Niehaus et al. 2014). Based on predicted function of the five $F U B$ genes and previous biochemical studies (Stipanovic et al. 2011b), a biosynthetic pathway for FA was proposed (Brown et al. 2012). The proposed pathway begins when the $F U B 1$-encoded PKS catalyzes formation of a six-carbon chain and, then, the FUB3-encoded amino acid kinase catalyzes linkage of the polyketide to oxaloacetate and a nitrogen atom.

After the initial descriptions of the five-gene $F U B$ cluster, we examined gene expression in genomic regions flanking the cluster in $F$. verticillioides and identified a region located 14.6 $\mathrm{kb}$ upstream of FUBl that included seven contiguous genes with patterns of expression similar to those of $F U B$ genes (this study). Thus, the goal of the current study was to determine whether these seven genes as well as FUB2 through FUB5 are required for FA production in $F$. verticillioides and $F$. oxysporum. The results provide evidence that FUB3 through $F U B 5$ as well as five genes within the seven-gene region are required for wild-type FA production. These results, combined with the presence of homologs of the seven-gene region near the FUB cluster in F. fujikuroi, indicate that the Fusarium FUB cluster consists of at least 12 genes rather than five genes, as originally described. The results also indicate that FA production is not required for wild-type levels of virulence in $F$. oxysporum and $F$. verticillioides. Together, the results of this study provide further insight into genetic and biochemical pathways required for FA biosynthesis and will help guide further studies to understand the role of FA in the ecology of Fusarium species.

\section{RESULTS}

Identification of genes with $\boldsymbol{F U B}$-like expression.

Microarray-based transcriptional analysis of $F$. verticillioides genes flanking the five-gene $F U B$ cluster identified seven contiguous genes (FVEG_12528 to FVEG_12534), located in a region $14.6 \mathrm{~kb}$ upstream from $F U B 1$, that exhibited patterns of expression similar to those of $F U B$ genes (Fig. 1). Namely, expression levels for the FUB genes and FVEG_12528 through FVEG_12534 were low at $24 \mathrm{~h}$, highest at $48 \mathrm{~h}$, and progressively lower at 72 and 96 h. FVEG_12528 through FVEG_ 12534 were predicted to encode four enzymes (two dehydrogenases, an oxidase, and a sulfhydrylase), a major facilitator superfamily (MFS) transporter, and two $\mathrm{Zn}(\mathrm{II})_{2} \mathrm{Cys}_{6}$ transcription factors (Table 1). All other predicted genes in the $58-\mathrm{kb}$ region $5^{\prime}$ of $F U B 1$ and the 16.6 -kb region $3^{\prime}$ of $F U B 5$, corresponding to the end of supercontig 20 in the $F$. verticillioides genome sequence database, exhibited very low levels of expression at all time points examined (Fig. 1). The four predicted genes, FVEG_12524 to FVEG_12527, in the 14.6-kb region between FUB1 and FVEG_12528 also exhibited very low levels of expression at the time points examined (Fig. 1), i.e., their patterns of expression were not the same as those of FUB1 through FUB5 and FVEG_12528 through FVEG_12534.

\section{Comparative genomic analysis.}

Examination of publicly available Fusarium genome sequences revealed that homologs of genes FVEG_12528 through FVEG_12534 are located in the same genomic region as homologs of FUB1 through FUB5 in F. fujikuroi and F. oxysporum (Table 2). The homologous genes share 90 to $99 \%$ deduced amino acid sequence identity in $F$. verticillioides, $F$. fujikuroi, and F. oxysporum (Table 3). Because of their FUB gene-like expression patterns in $F$. verticillioides, as well as additional evidence described below, we will, hereafter, refer to FVEG_12528 through FVEG_12534 and their homologs in other species as FUB6 through FUB12, respectively (Fig. 2). In addition, in the description of the $F U B$ region immediately below, we use the gene models predicted for $F$. oxysporum $\mathrm{f}$. sp. lycopersici Fol4287 as representative of F. oxysporum.

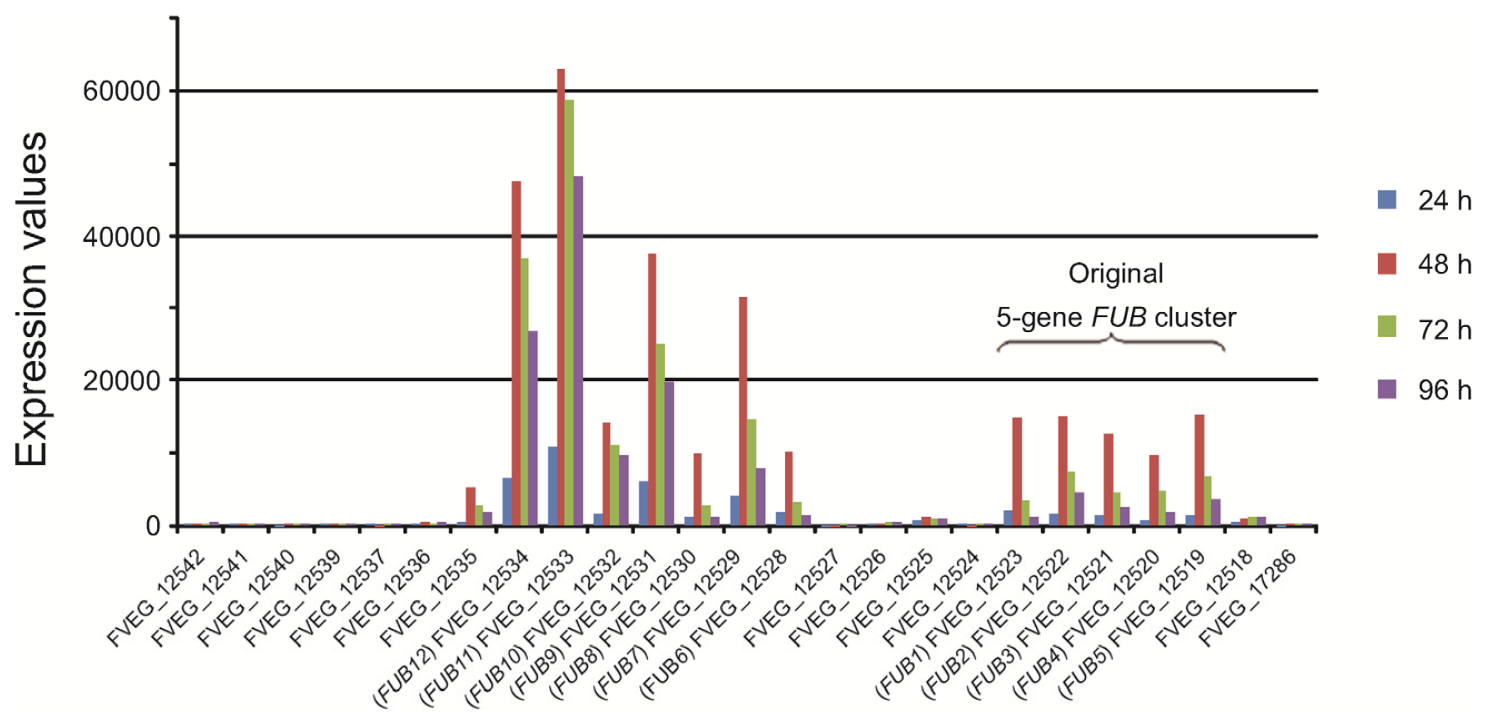

Fig. 1. Microarray-based analysis of gene expression in the FUB cluster region in Fusarium verticillioides grown for 24 to 96 h in GYAM medium ( 0.24 M glucose, $0.05 \%$ yeast extract, $8 \mathrm{mM}$-asparagine, $5 \mathrm{mM}$ malic acid, $1.7 \mathrm{mM} \mathrm{NaCl}, 4.4 \mathrm{mM} \mathrm{K}_{2} \mathrm{HPO}_{4}, 2 \mathrm{mM} \mathrm{MgSO}_{4}$, and $8.8 \mathrm{mM} \mathrm{CaCl}_{2}$, $\mathrm{mH}_{3.0}$ ). 
The order and orientation of the FUB6 through FUB12 homologs are the same in all three Fusarium species; however, the position of the FUB6 through FUB12 segment relative to the FUB1 through FUB5 segment differs in $F$. verticillioides compared with the other species, i.e., in F. verticillioides, the
FUB6 through FUB12 segment is located $5^{\prime}$ of $F U B 1$, whereas in $F$. fujikuroi and $F$. oxysporum, it is located $3^{\prime}$ of $F U B 5$, and the entire FUB6 through FUB12 segment is inverted relative to $F$. verticillioides (Fig. 2). The distance between the FUBI through FUB5 and FUB6 through FUB12 segments differs in

Table 1. Predicted functions of genes in the Fusarium verticillioides FUB cluster region

\begin{tabular}{|c|c|c|c|c|c|}
\hline FCD designation ${ }^{\mathrm{s}}$ & Gene name & Predicted function $^{\mathrm{t}}$ & BLAST E value $^{u}$ & NCBI-CDD domain model & Delete/Comp. ${ }^{v}$ \\
\hline FVEG_12535 & & Methyltransferase & $1.1 \times 10^{-23}$ & COG4122 & \\
\hline FVEG_12534 & FUB12 & C6 transcription factor & $1.5 \times 10^{-10}$ & CD12148 & $\mathrm{x}$ \\
\hline FVEG_12533 & FUB11 & $\mathrm{MFS}^{\mathrm{w}}$ & $2.3 \times 10^{-15}$ & CD06174 & $\mathrm{x} / \mathrm{c}$ \\
\hline FVEG_12532 & FUB10 & C6 transcription factor & $4.3 \times 10^{-4}$ & CD00067 & $\mathrm{x} / \mathrm{c}$ \\
\hline FVEG_12531 & FUB9 & Oxidase & $9.9 \times 10^{-85}$ & CD02809 & $(\mathrm{x})$ \\
\hline FVEG_12530 & $F U B 8^{\mathrm{x}}$ & Dehydrogenase & $5.3 \times 10^{-26}$ & CD05235 & \\
\hline FVEG_12529 & FUB7 & Sulfhydrylase & $4.2 \times 10^{-154}$ & TIGR01326 & $\mathrm{x}$ \\
\hline FVEG_12528 & FUB6 & Dehydrogenase & $9.4 \times 10^{-74}$ & CD08295 & \\
\hline FVEG_12527 & & Aldolase & $8.2 \times 10^{-12}$ & COG0235 & \\
\hline FVEG_12526 & & Lactamase & $7.6 \times 10^{-8}$ & SMART00849 & \\
\hline FVEG_12525 & & Dehydrogenase & $2.0 \times 10^{-36}$ & CD00567 & \\
\hline FVEG_12524 & & Esterase & $7.0 \times 10^{-34}$ & PFAM00135 & \\
\hline FVEG_12523 & FUB1 & $\mathrm{PKS}^{\mathrm{y}}$ & $1.2 \times 10^{-133}$ & CD00833 & $\mathrm{x}$ \\
\hline FVEG_12522 & FUB2 & Unknown & na & na & $\mathrm{x}$ \\
\hline FVEG_12521 & FUB3 & Amino acid kinase & $1.9 \times 10^{-102}$ & CD04247 & $\mathrm{x}$ \\
\hline FVEG_12520 & FUB4 & Hydrolase & $1.5 \times 10^{-9}$ & PFAM03959 & $\mathrm{x} / \mathrm{c}$ \\
\hline FVEG_12519 & FUB5 & Acetyltransferase & $1.3 \times 10^{-79}$ & COG2021 & $\mathrm{x} / \mathrm{c}$ \\
\hline $\mathrm{Np}^{\mathrm{z}}$ & & Unknown & na & na & \\
\hline FVEG_12518 & & Unknown (WD40) & $5.6 \times 10^{-48}$ & CD00200 & \\
\hline
\end{tabular}

${ }^{s}$ Designations from the Fusarium Comparative Database (FCD) at the Broad Institute. Gene designations in bold text are coexpressed during growth on

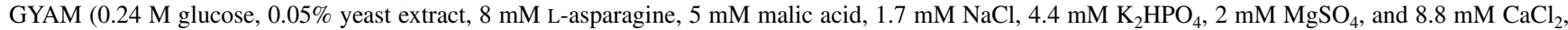
$\mathrm{pH} 3.0)$.

${ }^{\mathrm{t}}$ Functions listed are based on the results of BLAST analysis.

" BLAST E value refers to the probability score, generated by BLASTX of each gene against the National Center for Biotechnology Information (NCBI) database to protein domain models in the Conserved Domain Database (CDD).

$\mathrm{v}$ The $\mathrm{x}$ indicates that the gene was deleted and $\mathrm{c}$ indicates that one of the gene deletion mutants was complemented with a wild-type copy of the gene.

${ }^{\mathrm{w}} \mathrm{MFS}=$ major facilitator superfamily, a group of transporters that facilitate the transport of a variety of substrates across membranes.

${ }^{x}$ The FUB8 predicted protein includes three domains with similarity to domains in the CDD. In addition to the dehydrogenase domain, Fub8 has a phosphopantetheine attachment site $\left(\right.$ PFAM00550, $\left.5.1 \times 10^{-3}\right)$ and a fatty acid CoA ligase domain $\left(\mathrm{CD} 05956,7.0 \times 10^{-12}\right)$.

${ }^{\text {y }} \mathrm{PKS}=$ polyketide synthase. The FUB1 predicted protein includes five domains with similarity to domains in the CDD. CD00833 corresponds to the highly conserved and signature keto synthase domain associated with PKS.

${ }^{\mathrm{z}} \mathrm{Np}=$ not predicted. The putative gene was predicted based on the presence of an open reading frame.

\section{F. verticillioides}

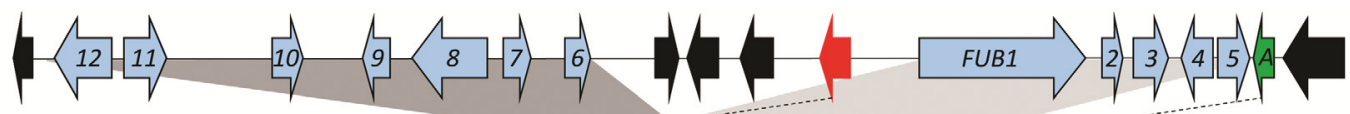

\section{F. fujikuroi}

\section{F. oxysporum}

Fo5176, PHW808, PHW815, HDV247, CL57, 26406 and II5

\section{F. oxysporum \\ FOL 4287, Fo47, FOSC 3-a, 25433 and MN25}

\section{Trichoderma} atroviride

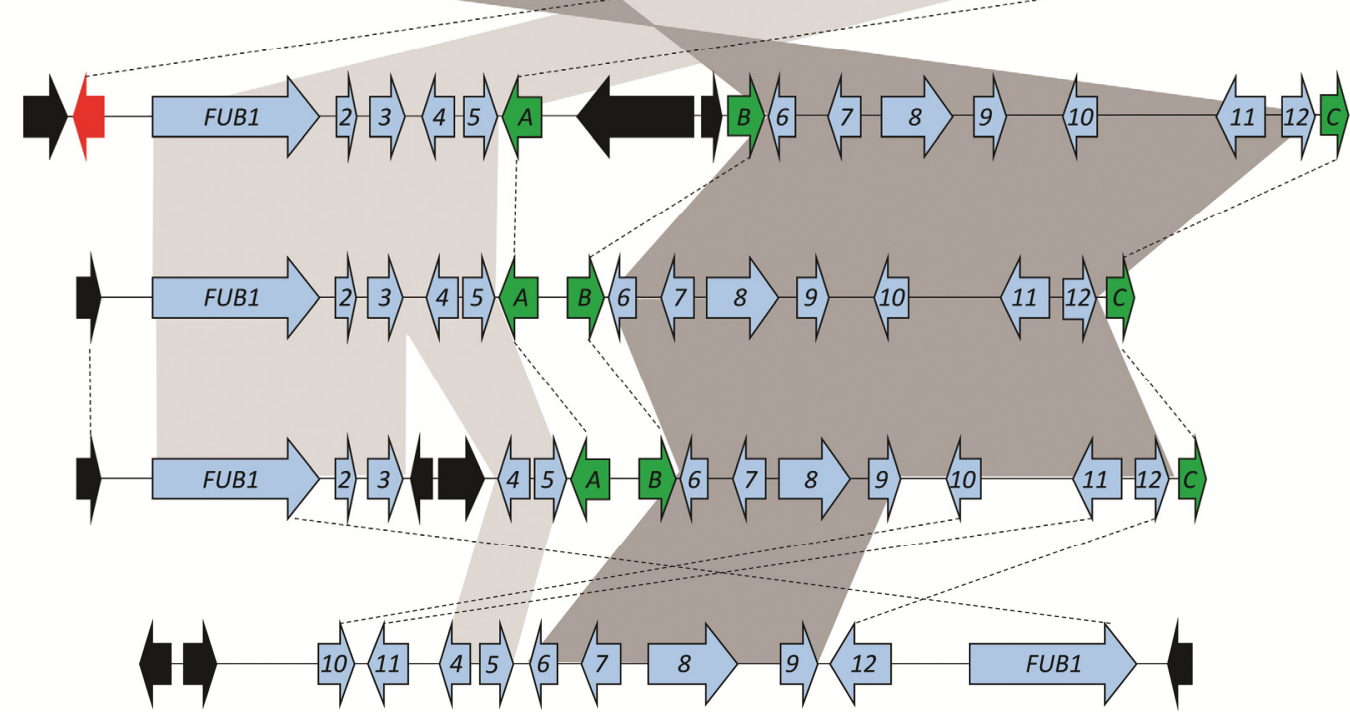

Fig. 2. Comparison of homologs of the FUB cluster region in Fusarium verticillioides, F. fujikuroi, 12 strains of F. oxysporum and Trichoderma atroviride. The genes considered to be part of the cluster are represented as blue arrows (FUB2 through FUB12 are labeled 2 through 12 ). The three green arrows (labeled A to $\mathrm{C}$ ) and the red arrow represent genes with homologs in the three Fusarium species but that exhibit markedly different patterns of expression than $F U B$ genes, according to expression analysis in $F$. verticillioides. In $F$. verticillioides, A is 450 bp and, thus, is truncated relative to homologs in $F$. fujikuroi and $F$. oxysporum, which are approximately $1,423 \mathrm{bp}$. Black arrows represent genes unique to each species. Gray shading indicates segments within the $F U B$ cluster that exhibit conservation of gene order among species. 
all three species: $4.9 \mathrm{~kb}$ in $F$. oxysporum, $10.5 \mathrm{~kb}$ in $F$. $f u$ jikuroi, and $14.6 \mathrm{~kb}$ in $F$. verticillioides. The 4.9-kb region in F. oxysporum includes two predicted genes, FOXG_21865 and FOXG_15242, that do not exhibit significant similarity to the genes between the FUB1 through FUB5 and FUB6 through $F U B 12$ segments in $F$. verticillioides. However, in $F$. verticillioides, there is a truncated homolog of FOXG_21865 (gene labeled A in Figure 2) located immediately $3^{\prime}$ to FUB5. This F. verticillioides FOXG_21865 homolog is predicted to encode a 152-amino acid protein, which is only about $42 \%$ the length of the FOXG_21865 predicted protein. In F. fujikuroi, the $10.5-\mathrm{kb}$ region between the FUB1 through FUB5 and FUB6 through FUB12 segments includes four predicted genes. One of these genes (FFUJ_02112) is a homolog of
FOXG_15242 (labeled B in Figure 2), and a second is a homolog of FOXG_21865 but is not annotated in the Institute of Bioinformatics and Systems Biology (IBIS) F. fujikuroi genome database. The position of these two $F$. fujikuroi genes in relation to FUB5 and FUB6 are conserved in $F$. fujikuroi and $F$. oxysporum (Fig. 2). The other two predicted $F$. fujikuroi genes located between the FUB1 to FUB5 and FUB6 to FUB12 segments are FFUJ_02110 and FFUJ_ 02111 and are predicted to encode two different proteins of unknown function (Fig. 2). Neither of the latter two F. fujikuroi genes have homologs near the $F U B$ cluster in $F$. oxysporum or $F$. verticillioides. The four predicted $F$. verticillioides genes located between the FUB1 to FUB5 and FUB6 to FUB12 segments do not have homologs in the corresponding region

Table 2. Predicted functions of genes in the Fusarium oxysporum FUB cluster region

\begin{tabular}{|c|c|c|c|c|c|c|}
\hline FCD designation $^{t}$ & Gene name & Proteins (aa) & Predicted function $^{u}$ & BLAST E-value $^{\mathrm{v}}$ & NCBI-CDD domain model & Deletion \\
\hline FOXG $21868^{w}$ & & 534 & Esterase & 0.0 & COG2272 & $\mathrm{x}$ \\
\hline FOXG 15253 & & 515 & Permease (MFS) & $2.4 \times 10^{-30}$ & TIGR02332 & $\mathrm{x}$ \\
\hline FOXG 15252 & & 899 & Rhamnosidase & $1.2 \times 10^{-170}$ & PFAM05592 & $\mathrm{x}$ \\
\hline FOXG 15251 & & 1,012 & Unknown & na & na & \\
\hline FOXG 15250 & & 750 & Glucosidase & $2.9 \times 10^{-40}$ & PFAM00933 & $\mathrm{x}$ \\
\hline FOXG 15249 & & 304 & Epimerase & $5.1 \times 10^{-21}$ & CD05234 & $\mathrm{x}$ \\
\hline FOXG 15248 & $F U B 1$ & 2,410 & Polyketide synthase & $9.7 \times 10^{-135}$ & CD00833 & $\mathrm{x}$ \\
\hline $\mathrm{Np}^{\mathrm{x}}$ & $F U B 2$ & 104 & Unknown & na & na & \\
\hline FOXG 15247 & FUB3 & 511 & Amino acid kinase & $5.0 \times 10^{-96}$ & CD04247 & $\mathrm{x}$ \\
\hline $\mathrm{Np}$ & & 393 & HET $^{\mathrm{y}}$ & $2.3 \times 10^{-16}$ & PFAM06985 & \\
\hline FOXG $21866^{\mathrm{Z}}$ & & 729 & Peptidase & $4.6 \times 10^{-3}$ & CD02619 & $\mathrm{x}$ \\
\hline FOXG 15244 & FUB4 & 267 & Hydrolase & $7.8 \times 10^{-10}$ & PFAM03959 & $\mathrm{x}$ \\
\hline FOXG 15243 & FUB5 & 464 & Acetyltransferase & $2.2 \times 10^{-77}$ & COG2021 & $\mathrm{x}$ \\
\hline FOXG 21865 & & 371 & Unknown & na & na & \\
\hline FOXG 15242 & & 378 & Reductase & $2.5 \times 10^{-25}$ & CD08249 & $\mathrm{x}$ \\
\hline FOXG 15241 & FUB6 & 358 & Dehydrogenase & $2.6 \times 10^{-73}$ & CD08295 & $\mathrm{x}$ \\
\hline FOXG 15240 & FUB7 & 434 & Sulfhydrylase & $1.0 \times 10^{-154}$ & TIGR01326 & $\mathrm{x}$ \\
\hline FOXG 15239 & FUB 8 & 1,059 & Dehydrogenase & $1.2 \times 10^{-6}$ & CD0523 & $\mathrm{x}$ \\
\hline FOXG 15238 & FUB 9 & 349 & Oxidase & 0.0 & CD02809 & $\mathrm{x}$ \\
\hline FOXG 15237 & FUB10 & 452 & C6 transcription factor & $9.8 \times 10^{-4}$ & CD00067 & $\mathrm{x}$ \\
\hline FOXG 15236 & FUB11 & 593 & $\mathrm{MFS}^{\mathrm{z}}$ & 0.0 & CD06174 & \\
\hline FOXG 15235 & FUB 12 & 723 & C6 transcription factor & $2.3 \times 10^{-10}$ & CD12148 & \\
\hline FOXG 15234 & & & C6 transcription factor & $1.1 \times 10^{-6}$ & CD00067 & \\
\hline
\end{tabular}

${ }^{\mathrm{t}}$ Designations from the Fusarium Comparative Database (FCD) at the Broad Institute.

" Putative functions listed are based on the results of BLAST analysis.

${ }^{v}$ BLAST E value refers to the probability score, generated by BLASTX of each gene against the National Center for Biotechnology Information (NCBI) database to protein domain models in the Conserved Domain Database (CDD).

${ }^{\mathrm{w}}$ Formerly FOXG_15254 and FOXG_15255.

${ }^{x} \mathrm{~Np}=$ not predicted. The putative gene was predicted based on the presence of an open reading frame and similarity to $F v F U B 2$.

${ }^{\mathrm{y}} \mathrm{HET}=\mathrm{a}$ vegetative incompatibility protein; MFS = major facilitator superfamily, a group of transporters that facilitate the transport of a variety of substrates across membranes.

${ }^{\mathrm{z}}$ Formerly FOXG_15245 and FOXG_15246.

Table 3. Comparison of FUB homologs

\begin{tabular}{|c|c|c|c|c|c|c|c|c|c|c|c|}
\hline $\begin{array}{l}\text { Gene } \\
\text { name }\end{array}$ & FVEG_\#w & $\begin{array}{l}\text { Proteins } \\
\text { (aa) }\end{array}$ & FOXG_\# & $\begin{array}{c}\text { Proteins } \\
\text { (aa) }\end{array}$ & Fv to $F^{x}$ & FFUJ_\# & $\begin{array}{c}\text { Proteins } \\
\text { (aa) }\end{array}$ & Fv to Ff & $\begin{array}{c}\text { T. atroviride } \\
\text { JGI_\# }\end{array}$ & $\begin{array}{c}\text { Proteins } \\
\text { (aa) }\end{array}$ & Fv to Ta \\
\hline FUB1 & 12523 & 2,409 & 15248 & 2,410 & 94.7 & 02105 & 2,410 & 93.7 & 211357 & 2,422 & 55.6 \\
\hline$F U B 2$ & 12522 & 109 & $\mathrm{Ng}^{\mathrm{y}}$ & 104 & 96.2 & 02106 & 104 & 98.1 & $\mathrm{Nh}^{\mathrm{z}}$ & - & - \\
\hline FUB3 & 12521 & 510 & 15247 & 511 & 96.3 & 02107 & 510 & 95.3 & $\mathrm{Nh}$ & - & - \\
\hline FUB4 & 12520 & 267 & 15244 & 267 & 97.0 & 02108 & 267 & 97.0 & 314350 & 271 & 59.2 \\
\hline FUB5 & 12519 & 463 & 15243 & 464 & 90.4 & 02109 & 427 & 92.6 & 260926 & 404 & 62.4 \\
\hline FUB6 & 12528 & 357 & 15241 & 358 & 96.6 & 02113 & 337 & 96.7 & 53082 & 356 & 72.2 \\
\hline FUB7 & 12529 & 433 & 15240 & 434 & 99.1 & 02114 & 433 & 98.9 & 93352 & 434 & 74.8 \\
\hline$F U B 8$ & 12530 & 1,036 & 15239 & 1,059 & 92.3 & 02115 & 1,036 & 91.1 & 52932 & 1,067 & 54.6 \\
\hline FUB 9 & 12531 & 387 & 15238 & 349 & 96.6 & 02116 & 358 & 97.2 & 314346 & 367 & 67.2 \\
\hline FUB10 & 12532 & 421 & 15237 & 453 & 97.8 & 02117 & 419 & 97.4 & 314352 & 378 & 39.8 \\
\hline FUB11 & 12533 & 593 & 15236 & 594 & 97.8 & 02118 & 574 & 96.3 & 53012 & 547 & 49.1 \\
\hline$F U B 12$ & 12534 & 661 & 15235 & 662 & 96.1 & 02119 & 661 & 96.7 & 211358 & 672 & 46.2 \\
\hline
\end{tabular}

${ }^{\text {w }}$ Designations for the FUB genes at the Fusarium Comparative Database at the Broad Institute for F. verticillioides (Fv) and F. oxysporum (Fo), at the Munich Information Center for Protein Sequences for F. fujikuroi (Ff), and the Joint Genome Institute (JGI) for Trichoderma atroviride (Ta).

${ }^{x} \mathrm{Fv}$ to Fo, Fv to Ff, and Fv to Ta refers to the percent amino acid identity shared between the $F$. verticillioides predicted proteins and the $F$. oxysporum, $F$. fujikuroi, and T. atroviride homologous proteins respectively.

${ }^{\text {y }} \mathrm{Ng}=$ No gene model available.

${ }^{\mathrm{z}} \mathrm{Nh}=$ No homolog in cluster. 
in either $F$. fujikuroi or $F$. oxysporum. However, the gene (FVEG_12524) immediately $5^{\prime}$ to FUBI in F. verticillioides (illustrated in red in Figure 2) has a homolog (FFUJ_02103) immediately $5^{\prime}$ to FUB1 in F. fujikuroi (Fig. 2).

BLASTX analysis of the $12 F$. verticillioides $F U B$ homologs against the National Center for Biotechnology Information (NCBI) NR database revealed homologs of FUB1 and FUB4 through $F U B 12$ in the genome sequence of Trichoderma atroviride (Fig. 2). The presence of a FUB1 homolog in T. atroviride is consistent with a recent phylogenomic analysis of PKS-encoding genes in Trichoderma spp. (Baker et al. 2012). Six of the T. atroviride FUB homologs (FUB4 through FUB9) are organized in the same order and orientation as in $F$. fujikuroi and $F$. oxysporum, albeit without additional genes between FUB5 and FUB6. Predicted proteins encoded by T. atroviride $F U B 1$ and $F U B 4$ to $F U B 12$ exhibit 40 to $75 \%$ deduced amino acid sequence identity to their respective Fusarium homologs (Table 3). The genes flanking either side of the $T$. atroviride $F U B$ regions exhibit no significant identity to the genes on either side of the $F U B$ region in Fusarium spp. Although a homolog of FUB3 is not present in the T. atroviride FUB region, a predicted gene (TRIATDRAFT_129821) with $53.5 \%$ deduced amino acid sequence identity to Fusarium FUB3 homologs is located $717 \mathrm{~kb}$ downstream of FUB1 in the $T$. atroviride genome sequence. However, phylogenetic analysis using the deduced amino acid sequence of TRIATDRAFT 129821 suggests it did not originate in the FUB cluster, because the sequence is more closely related to aspartate kinaselike proteins in Fusarium and Trichoderma spp. that are not encoded in the FUB cluster than it is to Fusarium FUB3 homologs (Supplementary Fig. 2; Supplementary Table 3). BLAST analysis did not identify a FUB2 homolog in the $T$. atroviride genome nor any $F U B$ homologs in the five other Trichoderma genome sequences in the Joint Genome Institute (JGI) and NCBI databases.

\section{Functional analysis of $F U B$ genes in $F$. verticillioides.}

For deletion analysis of FUB2 through FUB12 in F. verticillioides, 1,111 hygromycin-resistant transformants were screened by polymerase chain reaction (PCR) to determine whether the coding regions of FUB2 through FUB12 had been deleted (Supplementary Table 4). No deletion mutants were recovered for

Table 4. Analysis of fusaric acid (FA) production in strains of Fusarium verticillioides and F. oxysporum examined in this study

\begin{tabular}{|c|c|c|c|c|}
\hline \multirow[t]{2}{*}{ Genes } & \multicolumn{2}{|c|}{ Fusarium verticillioides } & \multicolumn{2}{|c|}{ Fusarium oxysporum } \\
\hline & Strains $^{\mathrm{u}}$ & FA production (\% wild type $)^{v}$ & Strains & FA production (\% wild type $)^{\mathrm{w}}$ \\
\hline FOXG_21868 & $\mathrm{nh}^{\mathrm{x}}$ & & $\Delta 21868$ & 130 \\
\hline FOXG_15253 & $\mathrm{nh}$ & & $\Delta 15253$ & $\mathrm{nt}$ \\
\hline FOXG_15252 & $\mathrm{nh}$ & & $\Delta 15252$ & 68 \\
\hline FOXG_-15251 & $\mathrm{nh}$ & & $n a^{y}$ & \\
\hline FOXG_15250 & $\mathrm{nh}$ & & $\Delta 15250$ & 56 \\
\hline FOXG_15249 & $\mathrm{nh}$ & & $\Delta 15249$ & 66 \\
\hline \multirow{2}{*}{ FUB1 } & $\Delta$ FvFub1.1 & 0 & $\Delta$ FoFub1.5 & 5 \\
\hline & $\Delta$ FvFub1.5 & 0.7 & na & \\
\hline \multirow[t]{2}{*}{ FUB2 } & $\Delta$ FvFub2.2 & 115 & na & \\
\hline & $\Delta$ FvFub2.3 & 85 & na & \\
\hline \multirow[t]{2}{*}{ FUB3 } & $\Delta$ FvFub3.4 & 13 & $\Delta$ FoFub3.9 & 0 \\
\hline & $\Delta$ FvFub3.11 & 7 & $\Delta$ FoFub3.22 & 0 \\
\hline FOXG_21866 & $\mathrm{nh}^{\mathrm{x}}$ & & $\Delta 21866$ & 66 \\
\hline \multirow[t]{3}{*}{ FUB4 } & $\Delta$ FvFub4.9 & 0 & $\Delta$ FoFub4.1 & $\mathrm{nt}$ \\
\hline & $\Delta$ FvFub4.43 & 0 & $\Delta$ FoFub4.6 & $\mathrm{nt}$ \\
\hline & $\Delta$ FvFub4.9AB8 & 163 & na & \\
\hline \multirow[t]{4}{*}{ FUB5 } & $\Delta$ FvFub5.1 & 8 & $\Delta$ FoFub5.9 & nt \\
\hline & $\Delta$ FvFub5.3 & 4 & $\Delta$ FoFub5.12 & $\mathrm{nt}$ \\
\hline & $\Delta$ FvFub5.1AB8 & 88 & na & \\
\hline & $\mathrm{nh}$ & & $\Delta 15242$ & 99 \\
\hline \multirow[t]{2}{*}{ FUB6 } & na & & $\Delta$ FoFub6.7 & 0 \\
\hline & na & & $\Delta$ foFub6.2 & nt \\
\hline \multirow[t]{2}{*}{ FUB7 } & na & & $\Delta$ FoFub7.7 & 56 \\
\hline & na & & $\Delta$ FoFub7.5 & nt \\
\hline \multirow[t]{2}{*}{ FUB 8} & na & & $\Delta$ FoFub8.30 & 0 \\
\hline & na & & $\Delta$ FoFub8.32 & 0 \\
\hline \multirow[t]{2}{*}{ FUB6 to FUB9 } & $\Delta$ FvFub69.2 & 0 & na & \\
\hline & $\Delta$ FvFub69.12 & 0 & na & \\
\hline FUB9 & $\Delta$ FvFub9.29 & 80 & $\Delta$ FoFub9.9 & $\mathrm{nt}$ \\
\hline \multirow[t]{3}{*}{ FUB10 } & $\Delta$ FvFub10.2 & 0 & $\Delta$ FoFub10.1 & 0 \\
\hline & $\Delta$ FvFub10.5 & 0 & $\Delta$ FoFub10.3 & 0 \\
\hline & $\Delta$ FvFub10.5AB815 & $389^{z}$ & na & \\
\hline \multirow{3}{*}{ FUB11 } & $\Delta$ FvFub11.6 & 0 & na & \\
\hline & $\Delta$ FvFub11.8 & 10 & na & \\
\hline & $\Delta$ FvFub11.8AB4 & 118 & na & \\
\hline \multirow{2}{*}{ FUB 12} & $\Delta$ FvFub12.54 & 18 & na & \\
\hline & $\Delta$ FvFub12.60 & 31 & na & \\
\hline
\end{tabular}

u The $\Delta$ symbol in a strain designation indicates that the strain has a deleted gene; AB indicates the deleted gene has been complemented.

${ }^{\vee}$ FA production reported is relative to wild type, by percent. Not all mutants were examined for FA production at the same time. For mutants of $F U B 1$ to FUB5 and FUB10 to FUB12, the mean level of FA production for the wild type was $19.2 \pm 5.8 \mu \mathrm{g} / \mathrm{ml}$. For mutants of $F U B 9$ and the $4-F U B$ gene mutants, the mean level of FA production for the wild type was $30.1 \pm 2.6 \mu \mathrm{g} / \mathrm{ml}$. For mutants of $F U B 10$ and FUB11, the mean level of FA production for the wild type was $6.6 \pm 0.5 \mu \mathrm{g} / \mathrm{ml}$.

${ }^{\mathrm{w}} \mathrm{FA}$ production reported is relative to wild type, by percent. All mutants were examined for FA production at the same time. The mean level of FA production for the wild type was $13.1 \pm 3.1 \mu \mathrm{g} / \mathrm{ml}$. $\mathrm{nt}=$ not tested

${ }^{\mathrm{x}} \mathrm{nh}=$ no homolog present

${ }^{\mathrm{y}}$ na $=$ deletion mutant not available.

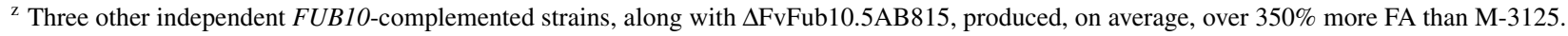


FUB6, FUB7, or FUB8, even though, collectively, 321 transformants were screened during attempts to individually delete these genes. In contrast, a screen of 140 transformants recovered following transformation with a DNA construct that simultaneously targeted FUB6, FUB7, FUB8, and FUB9 identified two mutants (fub6-9 mutants) in which the four genes were deleted. In total, 23 FUB-deletion mutants were identified. All transformants exhibited wild-type growth and conidiation on GYAM medium $(0.24 \mathrm{M}$ glucose, $0.05 \%$ yeast extract, $8 \mathrm{mM}$ L-asparagine, $5 \mathrm{mM}$ malic acid, $1.7 \mathrm{mM} \mathrm{NaCl}, 4.4 \mathrm{mM} \mathrm{K}_{2} \mathrm{HPO}_{4}, 2 \mathrm{mM}$ $\mathrm{MgSO}_{4}$, and $8.8 \mathrm{mM} \mathrm{CaCl}$, $\mathrm{pH} 3.0$ ), maize kernels, $\mathrm{V}-8$ juice agar, and yeast extract-peptone-glucose (YPG) agar. Liquid chromatography-tandem mass spectrometry (LC-MS/MS) analysis of mutants indicated that FA production was abolished in fub4, fub10, and fub6-9 mutants, was reduced by 76 to $95 \%$ relative to wild type in $f u b 3, f u b 5, f u b 11$, and fub12 mutants, and was unaltered in fub2 and fub9 mutants (Table 4).

For complementation analysis of selected fub4, fub5, fub10, and fubl1 mutants, geneticin-resistant transformants were screened for the presence of the FUB4, FUB5, FUB10, and $F U B 11$ coding sequences, respectively. LC-MS/MS analysis of culture extracts revealed that the FUB4, FUB5, and FUB11 complementation strains produced FA at levels that were 163 , 88 , and $118 \%$, respectively, of those produced by the wild type (Table 4). In contrast, the FUB10 complementation strain produced FA at levels that were over $350 \%$ of those produced by the wild type (Table 4).

\section{Functional analysis of $F U B$ genes in $F$. oxysporum.}

For deletion analysis of genes in the $F$. oxysporum $F U B$ cluster region, 10 to 30 transformants per transformation were arbitrarily selected for PCR analysis to determine if the target gene was replaced with the geneticin resistance gene $(\mathrm{GenR})$ (data not shown). A total of 16 predicted genes were deleted by double homologous recombination. All 59 transformants, both deletion mutants and mutants in which the transforming DNA inserted ectopically in the genome, exhibited wild-type growth and conidiation on Czapek-Dox broth (CDB), minimal medium (MM), and YPG agar and liquid media. High performance liquid chromatography (HPLC) analysis of 3-week-old CDB culture extracts of mutants indicated no FA was present in extracts of the fub3, fub6, fub8, and fublo mutants, while minimal FA (5\% of wild type) was observed in the fubl mutant. In contrast, significant levels of FA ( $56 \%$ of wild type) were observed in extracts of the fub7 mutant. FA production by the $f u b 4, f u b 5$, and $f u b 9$ mutants was not examined (Table 4). Deletion mutants of FOXG_15242 (located between FUB5 and $F U B 6$ ) and FOXG_21866 (located between FUB3 and $F U B 4$, and individual deletion mutants of the five genes immediately upstream of $F U B 1$ produced FA at levels ranging from 56 to $130 \%$ of wild-type levels.

\section{Pathogenicity of $f u b$ mutants.}

To assess the effect of FA production on pathogenicity, we examined severity of symptoms induced by $F$. oxysporum in an assay with the three-angled cactus and by $F$. verticillioides in a maize seedling assay. In the cactus assay, the severity of symp- toms induced by $F$. oxysporum fublo mutants was not consistently reduced compared with wild type and, in some cases, significant differences in severity were observed between the two mutants (Table 5; Fig. 3). In contrast, culture filtrates of the fub10 mutants were significantly less phytotoxic than filtrates from the wild-type progenitor. These results indicate that FA production is not required for wild-type levels of virulence of $F$. oxysporum on three-angled cactus under the conditions examined but that the ability to produce FA can contribute to phytotoxicity of $F$. oxysporum culture filtrates. The disease symptoms induced by inoculation with living $F$. oxysporum fublo mutants suggest that $F$. oxysporum produces other, nonsecreted virulence factors that are sufficient to cause disease. In the maize seedling assay, disease severity induced by fubl and fublo mutants of $F$. verticillioides did not differ significantly from their wild-type FA-producing progenitor (Supplementary Table 5).

\section{$F U B 10$ and gene expression.}

The complete loss of FA production in the $F$. verticillioides and $F$. oxysporum fublo mutants coupled with the similarity of the predicted $F U B 10$ protein (Fub10) to $\mathrm{Zn}(\mathrm{II})_{2} \mathrm{Cys}_{6}$ transcriptional regulators suggest that Fub10 regulates expression of other FUB genes. To examine the effect of FUB10 on FUB gene expression, we performed quantitative (q)PCR analysis of multiple $F$. verticillioides and $F$. oxysporum genes in the fub10 deletion mutants and wild type.

In $F$. verticillioides, expression of $F U B 1, F U B 3, F U B 8$, and $F U B 10$ was assessed in fubl0 deletion mutants $\triangle$ FvFub10.2 and $\triangle$ FvFub10.5, the FUB10 complementation strain $\triangle$ FvFub10.5AB815, and the wild-type progenitor strain (Table 6 ). In the wild-type strain, abundant transcripts of all four $F U B$ genes were detected, a result that is consistent with microarray results (Fig. 1). By contrast, in the fum10 deletion mutants, transcript levels for all four genes were minimal or undetectable. In the FUB10 complementation strain, FUB10 transcript levels were over threefold greater than in the wild type, and $F U B 1, F U B 3$, and FUB8 transcript levels were approximately 23-fold greater than in the wild type (Table 6). These data are consistent with Fub10 being a transcription factor that positively regulates transcription of genes in the $F U B$ cluster. In addition, the high levels of $F U B$ gene transcripts in the FUB10 complementation strain $\triangle \mathrm{FvFub} 10.5 \mathrm{AB} 815$ are consistent with the greater-than-wild-type levels of FA production for this and other FUB10 complementation strains (Table 3).

The greater FA production and $F U B$ gene transcription in the $F$. verticillioides $F U B 10$ complementation strain compared with the wild type could be due to higher levels of transcription from a single copy of $F U B 10$ resulting from the presence of multiple copies of FUB10 in complementation strain $\triangle$ FvFub10.5AB815 or from some other mechanism. qPCR analysis with $F U B 10$-specific primers of genomic DNA from the wild-type progenitor, fublo deletion mutants, and the FUB10 complementation strain revealed that the complementation strain contained 3.5-fold more FUB10 DNA than the wild type (Table 7). No FUB10 DNA was detected in the fub10 deletion mutants. Thus, the high levels of FA production and of FUB transcripts in the FUB10 complementation strain

Table 5. Pathogenicity of the selected Fusarium oxysporum transformants on cross sections of three-angled cactus shoots

\begin{tabular}{|c|c|c|c|c|}
\hline \multirow[b]{2}{*}{ Fungal strain } & \multicolumn{4}{|c|}{ Symptom severity } \\
\hline & Culture filtrate & Spore suspension $\left(1 \times 10^{4} / \mathrm{ml}\right)$ & Spore suspension $\left(1 \times 10^{6} / \mathrm{ml}\right)$ & Agar block \\
\hline Foxy20 (wild type) & $3.0 \pm 0.0 \mathrm{a}^{\mathrm{z}}$ & $2.5 \pm 0.5 \mathrm{a}$ & $4.5 \pm 0.5 \mathrm{a}$ & $4.0 \pm 0.0 \mathrm{a}$ \\
\hline$\Delta$ FoFub10.1 & $1.5 \pm 0.5 \mathrm{c}$ & $1.5 \pm 0.5 b$ & $4.5 \pm 0.5 \mathrm{a}$ & $3.2 \pm 1.0 \mathrm{~b}$ \\
\hline$\Delta$ FoFub1.1 & $2.5 \pm 0.5 b$ & $2.0 \pm 0.6 \mathrm{ab}$ & $3.7 \pm 0.8 b$ & $4.0 \pm 0.0 \mathrm{a}$ \\
\hline Control (CDB only) & $0.0 \pm 0.0 \mathrm{~d}$ & & & \\
\hline
\end{tabular}

z The same letters in each column denote no significant difference at $P<0.05$ by Duncan's multiple range test. 
are likely due to the presence of multiple copies of FUB10 in the genome of the complementation strain compared with the single copy of the gene in wild-type $F$. verticillioides.

In $F$. oxysporum, qPCR was conducted to assess expression of FUB1, FUB3 through FUB10, FOXG_15242, FOXG_21866, FOXG_15249 through FOXG_15253, and FOXB_21868 in the fublo deletion mutant $\Delta 15237$ and the wild-type progenitor strain Foxy20 (Fig. 4). All nine FUB genes examined were expressed more on $\mathrm{CDB}$ than in $\mathrm{MM}$ at all time points in the wild type, while none were expressed in the fublo deletion mutant (Fig. 4). These data are consistent with FA production by the wild type in $\mathrm{CDB}$ medium and no production in MM medium over the time course and further support the hypothesis that $F U B 10$ is a transcription factor that positively regulates transcription of $F U B$ genes. In contrast, the expression of FOXG_15242 (located between FUB5 and FUBO), FOXG

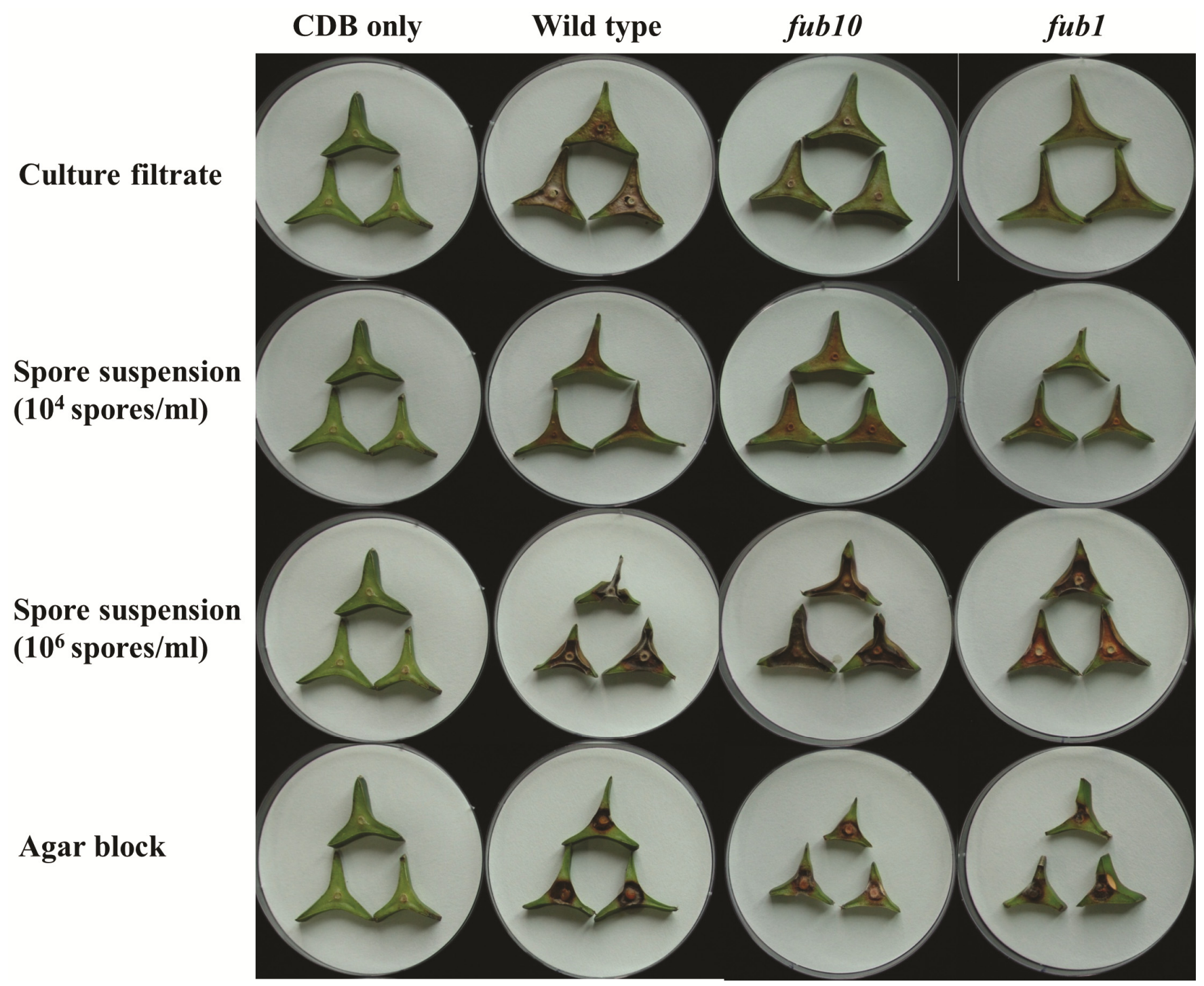

Fig. 3. Pathogenicity of Fusarium oxysporum strains on three-angled cactus (Hylocereus trigonus). Three 0.5 -cm-thick cross stem sections of the cactus were placed on moistened Whatman No. 2 filter papers in petri dishes. The central stem portions were treated with $0.1 \mathrm{ml}$ of the Czapek-Dox broth (CDB) culture filtrate, $0.1 \mathrm{ml}$ of spore suspensions with $10^{4}$ or $10^{6}$ spores per milliliter, or an agar block excised from a potato dextrose agar culture of the fubl mutant, fub10 mutant, or their wild-type progenitor strain Foxy20, were incubated for 4 days and, then, were assessed for disease symptoms.

Table 6. FUB gene expression in Fusarium verticillioides FUB10 deletion mutants and complementation strains by quantitative polymerase chain reaction

\begin{tabular}{lcccc}
\hline & \multicolumn{3}{c}{ Gene $^{\mathbf{x}}$} \\
\cline { 2 - 5 } Strains $^{\mathbf{w}}$ & $\boldsymbol{F U B 1}$ & $\boldsymbol{F U B 3}$ & $\boldsymbol{F U B \boldsymbol { B }}$ & $\boldsymbol{F U B 1 0}$ \\
\hline Wild type & $608 \mathrm{a}^{\mathrm{y}}$ & $393 \mathrm{a}$ & $454 \mathrm{a}$ & $261 \mathrm{a}$ \\
FUB10 deletion & $0.6 \mathrm{c}$ & $1.1 \mathrm{c}$ & $0.5 \mathrm{c}$ & $0.0 \mathrm{c}$ \\
FUB10 complementation & $12,980 \mathrm{~b}$ & $11,610 \mathrm{~b}$ & $8,260 \mathrm{~b}$ & $831 \mathrm{~b}$ \\
\hline
\end{tabular}

${ }^{w}$ Wild type refers to $F$. verticillioides strain M-3125, the parent strain of the FvFUB10 deletion mutants. Deletion refers to FUB10 deletion mutants $\triangle$ FvFub10.2 and $\triangle$ FvFub10.5 and complemented refers to $F U B 10$ complemented mutant $\triangle$ FvFub10.5AB815.

${ }^{x}$ Quantity of transcript in culture per gene in nanograms per microliter.

${ }^{y}$ Strain means for each gene (within a column) followed by different letters are significantly different based on differences of least squares means at $P<0.05$.

${ }^{\mathrm{z}}$ The deletion strain was not included in the analysis for FUB10 since the mean and variance were both zero and thus is automatically significantly lower than complemented mutant and wild type at $P<0.05$. 
21866 (located between FUB3 and FUB4), and the six genes downstream of FUB1 (FOXG_15249 through FOXG_15253 and FOXB_21868) were expressed both in CDB and MM in the wild type and in the fublo deletion mutant over time (data not shown). Although FUB gene expression did not generally increase over time, FA production was first detected at day six and increased linearly to day 21 (Supplementary Fig. 3). Consistent with transcript analysis, no FA was observed at any time point in the fublo deletion mutant.

\section{DISCUSSION}

Previous molecular genetic studies of $F$. verticillioides and $F$. fujikuroi provided evidence for a five-gene $F U B$ cluster
(Brown et al. 2012; Niehaus et al. 2014). In the current study, analyses of cluster flanking regions provide evidence that the Fusarium FUB cluster consists of 12 genes, including the five previously described $F U B$ genes. The evidence for this larger $F U B$ cluster is that the 12 genes exhibit similar patterns of expression, their order and orientation is largely conserved among the three Fusarium species examined, and nine of them are required for wild-type FA production in one or both $F$. $o x y$ sporum and $F$. verticillioides. Furthermore, there is a 10-gene homolog of the Fusarium FUB cluster in the $T$. atroviride genome (Fig. 2).

The previously described five-gene $F U B$ cluster did not include genes predicted to encode a transporter or transcription factor, two types of proteins frequently encoded by SM bio-

Table 7. Relative amount of FUB10 coding DNA in FUB10 complementation mutant genome by quantitative polymerase chain reaction (PCR)

\begin{tabular}{|c|c|c|c|c|c|c|c|}
\hline \multirow[b]{2}{*}{ Strains } & \multicolumn{3}{|c|}{ Average $\mathrm{Ct}$ values ${ }^{\mathrm{u}}$} & \multirow[b]{2}{*}{$\operatorname{Mean}^{v}$} & \multirow[b]{2}{*}{$\Delta \mathbf{C t}^{\mathbf{w}}$} & \multirow[b]{2}{*}{$\Delta \Delta \mathbf{C t}^{\mathbf{x}}$} & \multirow[b]{2}{*}{ Fold difference $^{\mathrm{y}}$} \\
\hline & FUB10 & $\boldsymbol{F U} \boldsymbol{U} 8$ & CYP2 & & & & \\
\hline FUB10 complementation ${ }^{\mathrm{z}}$ & 14.95 & 17.11 & 16.2 & 16.65 & -1.7 & -1.81 & 3.5 \\
\hline Wild type & 17.65 & 18.04 & 17.05 & 17.54 & 0.11 & & \\
\hline
\end{tabular}

u Average threshold cycle $(\mathrm{Ct})$ was calculated from three replica PCR reactions for each DNA.

${ }^{v}$ Geometric mean of the two control genes $F U B 8$ and $C Y P 2$ was calculated by multiplying the respective Ct values and taking the square root.

${ }^{\mathrm{w}} \Delta \mathrm{Ct}=F U B 10 \mathrm{Ct}$ (per strain) - mean $\mathrm{Ct}$.

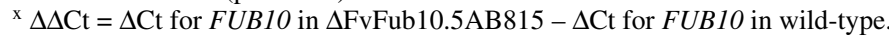

${ }^{y}$ Fold difference (FD) more FUB10 DNA in FUB10 complementation mutant $\triangle$ FvFub10.5AB815 as compared with the wild-type strain M-3125 was calculated using the formula $\mathrm{FD}=2^{-\Delta \Delta \mathrm{Ct}}$.

${ }^{\mathrm{z}}$ FUB10 complementation mutant $=\Delta$ FvFub10.5AB815.
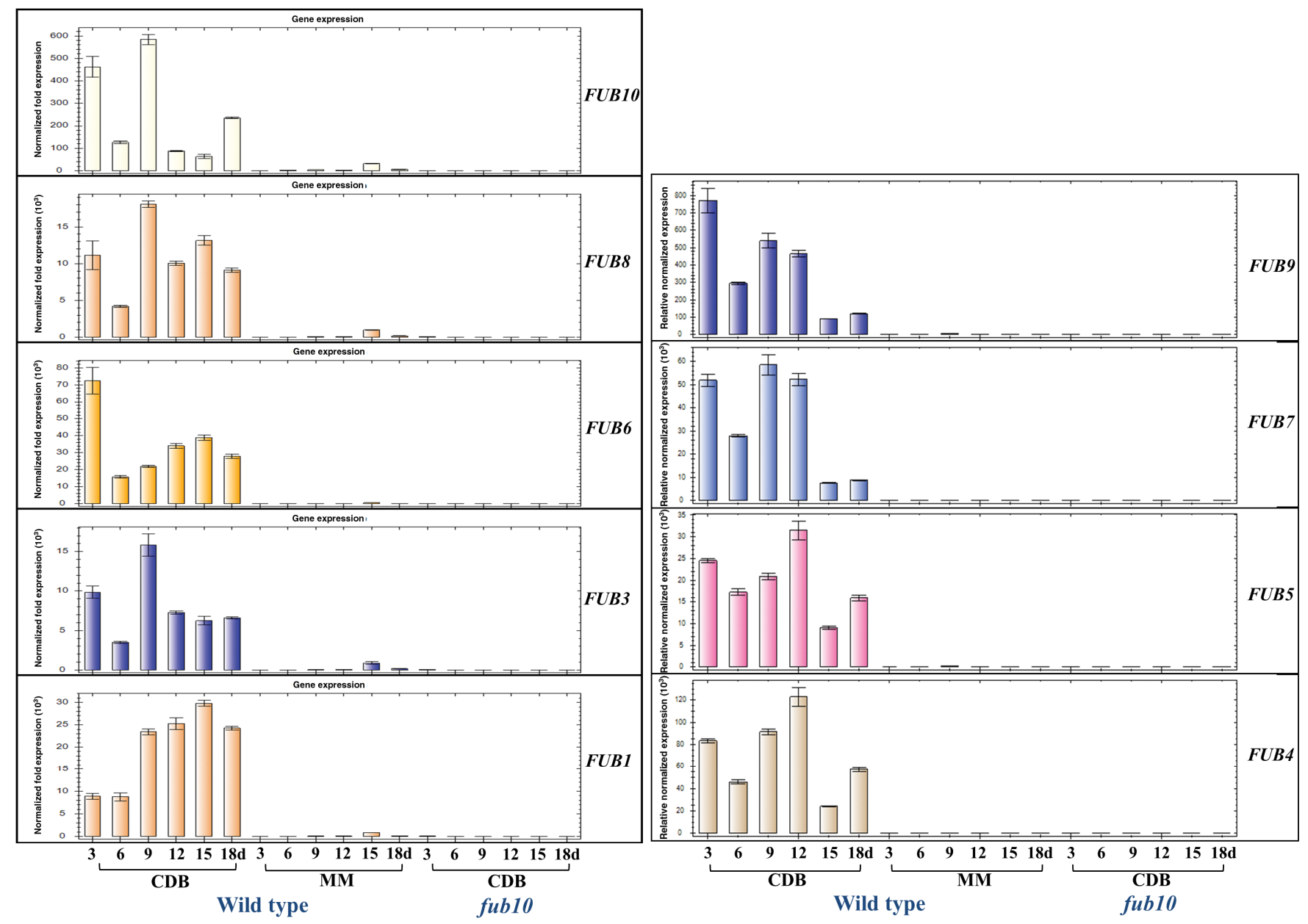

Fig. 4. Relative expression of nine Fusarium oxysporum FUB genes FUB1, FUB3, FUB4, FUB5, FUB6, FUB7, FUB8, FUB9, and FUB10 under fusaric acid producing (Czapek-Dox broth $[\mathrm{CDB}]$ ) and nonproducing conditions (minimal medium [MM]) over 18 days in wild-type strain Foxy20 and fub10 deletion mutant $\Delta 15237$. The standard errors are indicated on top of each histogram bar. 
synthetic gene clusters. The larger $F U B$ cluster described in the current study includes a gene, $F U B 11$, predicted to encode an MFS transporter and two genes, FUB10 and FUB12, predicted to encode $\mathrm{Zn}(\mathrm{II})_{2} \mathrm{Cys}_{6}$ transcription factors. In addition to the $\mathrm{Zn}(\mathrm{II})_{2} \mathrm{Cys}_{6}$ binuclear cluster DNA-binding domain, Fub12 is predicted to contain a fungal transcription factor regulatory domain. Thus, in addition to biosynthetic enzymes, the larger $F U B$ cluster is predicted to encode proteins that could be involved in transport of FA across the cell membrane (Fub11) and regulation of FUB gene expression (Fub10 and Fub12). The lack of FA production in fublo mutants and the reduced expression of multiple $F U B$ genes in fub10 mutants of both $F$. oxysporum and $F$. verticillioides suggest that Fub10 is a FA pathway-specific transcriptional regulator. Although the deletion of the other $F U B$ cluster transcription factor gene (FUB12) did not abolish FA production in F. verticillioides, the substantially reduced levels of FA in cultures of fubl2 mutants indicate that FUB12 likely contributes to regulation of FA production.

The 12-gene, Fusarium FUB cluster is unusual in that it consists of segments that are separated from one another by a 4.9- to $14.6-\mathrm{kb}$ region with putative non-FUB genes (Fig. 2). The evidence that these putative non- $F U B$ genes do not contribute to FA production is i) they are not conserved in the three FA-producing fusaria examined, ii) they are absent in the $F U B$ cluster homolog in $T$. atroviride, iii) in both $F$. oxysporum and $F$. verticillioides, the putative non- $F U B$ genes that were examined exhibited patterns of expression that differed from those of $F U B$ cluster genes, and iv) deletion of one of them (FOXG_15242) in $F$. oxysporum did not affect FA production. Because of the presence of the non-FUB genes within the $F U B$ cluster, the Fusarium cluster could also be viewed as two or three smaller clusters located near one another.

The presence of two non-FUB genes in the FUB3-FUB4 intergenic region of only some strains of $F$. oxysporum and their absence in the corresponding region of $F$. fujikuroi and $F$. verticillioides suggests that this non- $F U B$ segment arose in $F$. oxysporum after it diverged from the FFSC. In contrast, the non-FUB segment in the FUB5-FUB6 intergenic region is present in all strains of $F$. oxysporum examined and in $F$. fujikuroi, although in the latter species it includes two non- $F U B$ genes that are not in $F$. oxysporum. This suggests that the non-FUB segment between $F U B 5$ and $F U B 6$ arose earlier than the non$F U B$ segment between $F U B 3$ and FUB4. We are currently examining the $F U B$ cluster in a larger diversity of FA-producing fusaria to gain further insight into the origins of the non- $F U B$ segments.

The organization of SM biosynthetic genes into multiple segments, rather than a cluster of contiguous genes dedicated to the same biosynthetic pathway, has been observed in other fungi. In Neotyphodium lolii, 10 lol genes involved in biosynthesis of the indole-diterpenes lolitrems are located in three segments separated from one another by 16- or 35-kb AT-rich retrotransposon relics (Young et al. 2006). The interruption of the Fusarium FUB cluster differs from the interruption of the $N$. lolii lol cluster in that the non-FUB sequences in $F U B$-gene intergenic regions have no apparent relationship to transposons but, instead, are predicted to encode metabolic or regulatory proteins (e.g., peptidase, dehydrogenase, HET protein). In some Fusarium species, trichothecene biosynthetic (TRI) genes are organized into three segments: a one-gene, a one- or two-gene, and a 12- or 14-gene segment. However, the TRIgene segments differ from the $F U B$-gene segments in that they are distinct loci, and in $F$. graminearum, each of these TRI loci is on a different chromosome. Why the Fusarium FUB cluster is interrupted by one or two segments of non- $F U B$ genes and whether this arrangement provides an advantage is not clear.
We are analyzing the $F U B$ cluster in a phylogenetically wider range of fusaria and examining the role of FA production in the ecology of these fungi to address these issues.

In $F$. verticillioides, the FUB1 to FUB5 and FUB6 to FUB12 segments of the $F U B$ cluster have undergone translocation and inversion relative to one another when compared with the homologous segments in F. fujikuroi and F. oxysporum (Fig. 2). A similar type of rearrangement of genes has also occurred in the TRI cluster during the evolutionary history of trichothecene-producing fusaria (Proctor et al. 2009). That is, in some species, a three-gene segment of the TRI cluster was inverted and translocated from one end of the cluster to the other. The relatively close phylogenetic relationship of $F$. verticillioides and F. fujikuroi (O'Donnell et al. 2013) indicates that the translocation within the $F U B$ cluster occurred relatively recently.

Gene-function analyses done in $F$. verticillioides (current study) and $F$. fujikuroi (Neihaus et al. 2014) indicate that FUB4 was essential for FA production, whereas FUB3 and FUB5 are not essential but were required for wild-type levels of FA production. In contrast, in a similar analysis done with $F$. oxysporum, FUB3 was essential for production. The production of some FA by $F$. verticillioides and $F$. fujikuroi fub3 or fub5 mutants indicate that either the reaction catalyzed by these enzymes, a putative amino acid kinase and acetyltransferase, respectively, can occur spontaneously or that products of other genes can carry out the reaction, albeit at a lower efficiency. Why FA production was completely blocked in the $F$. oxysporum fub3 mutants is unclear. This result suggests, however, that if $F$. verticillioides and $F$. fujikuroi have a gene located outside the FUB cluster that can compensate for FUB3 deletion, a homolog of this noncluster gene is either absent or regulated differently in $F$. oxysporum.

In the current study, functional analysis of FUB6 through $F U B 12$ in $F$. verticillioides and $F$. oxysporum revealed that five of these genes play a role in FA synthesis. Surprisingly, both putative $\mathrm{Zn}(\mathrm{II})_{2} \mathrm{Cys}_{6}$ transcription factor genes (FUB10 and $F U B 12)$ appear to be involved; FUB10 is essential for FA production, whereas $F U B 12$ is not essential but, instead, is required for wild-type levels of production (Table 4). qPCR analysis indicated that FUB10 is required for transcription of other $F U B$ genes and, thus, appears to be a FA pathway-specific regulator (Table 6; Fig. 4). How FUB12 affects FA synthesis is not known, but our current hypothesis is that it modulates $F U B$ gene transcription in response to levels of exogenous FA. Preliminary evidence in support of this hypothesis includes a rapid increase in expression of FUB12 and the transporter gene, $F U B 11$, in response to the addition of FA to cultures of wildtype $F$. verticillioides (D. W. Brown, unpublished) and the $95 \%$ reduction in FA production in fubl1 mutants (Table 4).

A specific role for FUB3, FUB4, FUB5, FUB6, and FUB8 in synthesis of FA could not be assigned because no obvious FA intermediates were observed in culture extracts of the corresponding fub mutants (Fig. 5), and the biochemical mechanism by which FA is formed from a polyketide precursor remains unclear. Furthermore, the role of FUB2, FUB7, and $F U B 9$, which encode a small protein of unknown function, a sulfhydrylase, and an oxidase, respectively, in FA synthesis is even less clear, because their deletion did not affect FA production. The presence of SM cluster genes that do not appear to be required for synthesis of the corresponding SM under laboratory conditions has been previously observed. For example, TRII4 is a gene located in the trichothecene biosynthetic gene cluster of trichothecene-producing fusaria and is not required for trichothecene production in culture but appears to play a role in planta (Dyer et al. 2005). In addition, multiple genes in the aflatoxin biosynthetic gene cluster in Aspergillus flavus have not yet been assigned a role in synthesis (Yu 2012). 
Although FA production has not been reported in $T$. atroviride to our knowledge, the presence and clustering of $10 \mathrm{FUB}$ gene homologs in this fungus indicate that it has the genetic potential to produce FA or an FA-like metabolite. The largely syntenic organization of $F U B$ genes in the Fusarium and $T$. atroviride clusters suggests that the separation of the $F U B$ genes into two or three segments in the Fusarium cluster occurred after the Fusarium and Trichoderma clusters diverged from one another.

The knowledge that FUB6, FUB8, and FUB10 are essential for FA production could aid in development of novel strategies to limit FA production. Although FA production is not required by Fusarium spp. for pathogenesis on maize seedling or cactus, production is required for phytotoxicity of $F$. oxysporum culture extracts on cactus (this study). In addition, FA is phytotoxic to cotton (Stipanovic et al. 2011a) and has been shown to negatively affect a variety of microorganisms (Boonman et al. 2012; Pan et al. 2011; Son et al. 2008). The identification of the $F U B$ cluster and the creation of $F U B$ gene deletion and complementation strains will facilitate future studies aimed at understanding the biochemical pathway required for FA formation as well as the impact of FA on plant-parasite interactions and plant-associated microbial communities. Our results highlight the contribution and limitations of an integrated approach of both functional (gene deletion, pathogenicity, and plant toxicity) and genomic (transcriptomic and comparative genetic) analyses to understanding the production and function of SM in fungi.

\section{MATERIALS AND METHODS}

\section{Strains and media.}

The wild-type strain of $F$. verticillioides used in this study was M-3125 (NRRL 13447) (Leslie et al. 1992). The wildtype strain of $F$. oxysporum was Foxy20 (KACC 47718) (Lee et al. 2013). Wild-type $F$. verticillioides RNA was prepared from cultures grown in GYAM medium for 24, 48, 72, or $96 \mathrm{~h}$. RNA of $F$. verticillioides mutant strains was prepared from

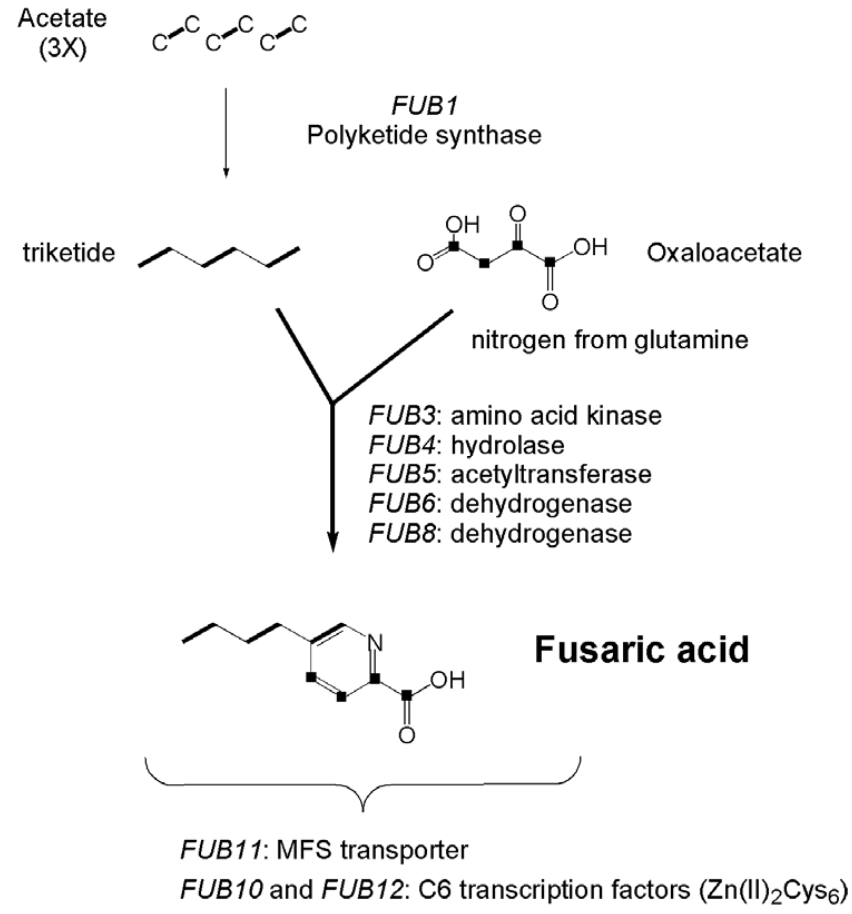

Fig. 5. Proposed biosynthetic pathway for fusaric acid biosynthesis in $F u$ sarium species. cultures grown in GYAM for $48 \mathrm{~h}$. RNA of $F$. oxysporum was prepared from cultures grown in CDB (MBCell, Seoul, Korea) and $\mathrm{MM}\left(1 \mathrm{~g}\right.$ of $\mathrm{KH}_{2} \mathrm{PO}_{4}, 0.5 \mathrm{~g}$ of $\mathrm{MgSO}_{4} \cdot 7 \mathrm{H}_{2} \mathrm{O}, 0.5 \mathrm{~g}$ of $\mathrm{KCl}$, $10 \mathrm{mg} \mathrm{FeSO} \cdot 7 \mathrm{H}_{2} \mathrm{O}, 30 \mathrm{~g}$ of sucrose, $2 \mathrm{~g}$ of $\mathrm{NaNO}_{3}$, and $0.2 \mathrm{ml}$ of trace elements) (Leslie and Summerell 2006) for 3, 6, 9, 12, 15 , and 18 days, in triplicate. FA production by $F$. verticillioides was determined from cracked maize kernel medium cultures grown for 10 days at $25^{\circ} \mathrm{C}$. The medium was prepared by autoclaving $2.5 \mathrm{~g}$ of cracked corn kernels and $1.2 \mathrm{ml}$ of distilled water in a 4-dram glass vial. Each vial was inoculated with a single $3-\mathrm{mm}^{2}$ mycelial plug taken from a V-8 juice agar (Tuite 1969) culture of $F$. verticillioides. FA production by $F$. oxysporum was determined from CDB shake cultures $(25 \mathrm{ml}$ of $\mathrm{CDB}$ in $50-\mathrm{ml}$ tubes incubated at $150 \mathrm{rpm}$ at $25^{\circ} \mathrm{C}$ ) inoculated with seven or eight $1-\mathrm{mm}^{2}$ mycelia plugs from a culture grown on potato dextrose agar (PDA) (Becton, Dickinson and Company, Sparks, MD, U.S.A.) or CDB stationary cultures $\left(20 \mathrm{ml}\right.$ of $\mathrm{CDB}$ in $90-\mathrm{mm}$ petri dishes at $\left.25^{\circ} \mathrm{C}\right)$ inoculated with $1 \times 10^{6}$ conidia per milliliter. Conidia were obtained by filtering a CMC (15 g of carboxymethylcellulose, $1 \mathrm{~g}$ of yeast extract, $0.5 \mathrm{~g}$ of $\mathrm{MgSO}_{4} \cdot 7 \mathrm{H}_{2} \mathrm{O}, 1 \mathrm{~g}$ of $\mathrm{NH}_{4} \mathrm{NO}_{3}, 1 \mathrm{~g}$ of $\mathrm{KH}_{2} \mathrm{PO}_{4}$ ) shake culture incubated at $150 \mathrm{rpm}$ at $25^{\circ} \mathrm{C}$ for 3 days through sterile Miracloth (Calbiochem).

\section{Gene identification.}

Possible functions of proteins encoded by the predicted genes flanking the five-gene $F U B$ cluster were assigned based on BLAST searches of the nonredundant sequence databases, using default parameters at the NCBI (Table 1) (Altschul et al. 1997). F. verticillioides and $F$. oxysporum nucleotide sequences were retrieved from the Fusarium Comparative database at the Broad Institute. F. fujikuroi nucleotide sequences were retrieved from the IBIS database (Wiemann et al. 2013). Transcript sequences were retrieved from the $F$. verticillioides Gene Index database at the Dana-Farber Cancer Institute (Brown et al. 2005). T. atroviride nucleotide sequences were retrieved from the JGI database. For each species, genomic DNA and coding region sequences recovered from a database were assembled with Sequencher (version 4.10.1; Gene Codes Corp., Ann Arbor, MI, U.S.A.) and DNASTAR Lasergene (version 7.1; DNASTAR, Madison, WI, U.S.A.) to confirm the positions of predicted start and stop codons as well as intron splice sites. These positions were modified manually in cases in which a gene model predicted by automatic annotation was deemed unlikely, based on cDNA sequences from the $F$. verticillioides Gene Index or from comparisons of sequences from different species.

\section{DNA preparation and PCR amplification.}

F. verticillioides genomic DNA used as template for PCR analysis was prepared using standard protocols (Sambrook et al. 2001) with minor modifications. Mycelia were scraped from one-week-old V-8 juice agar plates, were placed in 250 $\mu l$ of DNA extraction buffer $(200 \mathrm{mM}$ Tris, $\mathrm{pH} 8.0,250 \mathrm{mM}$ $\mathrm{NaCl}, 25 \mathrm{mM}$ ethylenediaminetetraacetic acid, $100 \mathrm{mg}$ of $0.5-$ $\mathrm{mm}$ glass beads [Scientific Industries, Inc., Bohemia, NY, U.S.A.] and $0.5 \%$ sodium dodecyl sulfate), were vortexed for 5 $\mathrm{min}$, and were incubated for $10 \mathrm{~min}$ at $65^{\circ} \mathrm{C}$. Phenol/chloroform/isoamyl alcohol $(25: 24: 1 ; 250 \mu \mathrm{l})$ was added to the mixture, followed by vortexing and centrifugation. The aqueous phase was transferred to a new tube and genomic DNA was isolated using UltraBind, following the manufacturer's directions (Mo Bio, Solana Beach, CA, U.S.A.). F. oxysporum DNA was prepared as described previously (Leslie and Summerell 2006).

PCR was performed with a total reaction volume of $10 \mu \mathrm{l}$ ( $5 \mu \mathrm{l}$ of Promega GoTaq master mix [Madison, WI, U.S.A.], 1 $\mu \mathrm{l}$ of each primer $[10 \mu \mathrm{M}]$, and $50 \mathrm{pg}$ of genomic DNA) in a MJ Research PTC-100 PCR thermocycler (Waltham, MA, 
U.S.A.), with the following program: $95^{\circ} \mathrm{C}$ for $30 \mathrm{~s}$, followed by $57^{\circ} \mathrm{C}$ for $30 \mathrm{~s}$, followed by $72^{\circ} \mathrm{C}$ for $90 \mathrm{~s}$ for 30 cycles.

\section{Microarray analysis.}

Microarrays were designed and produced by Roche NimbleGen (Madison, WI, U.S.A.) based on 12,414 gene models obtained from the Broad Institute and 875 unique expressed sequence tags from the $F$. verticillioides Gene Index. Each sequence was represented on the array by up to 12 unique 60-mer probes. Microarray hybridization, data acquisition, and initial analysis were conducted by Roche NimbleGen, Iceland. Data were normalized by robust multiarray average (Bolstad et al. 2003; Irizarry et al. 2003) and were compared using the Acuity 4.0 microarray analysis software package (Molecular Devices Corp, Sunnyvale, CA, U.S.A.). The GYAM experiment was conducted with three biological replicates for the wild-type strain after 24, 48, 72, and $96 \mathrm{~h}$. The array platform and experimental data set is available at Gene Expression Omnibus under accession number GSE16900.

\section{Gene deletion.}

Inactivation of $F$. verticillioides genes was accomplished by deletion of the predicted coding region of each gene via the split-marker and protoplast transformation methods with the hygromycin-resistance gene $(\mathrm{HygB})$ as the selectable marker (Catlett et al. 2002; Proctor et al. 1999), essentially as described previously (Brown et al. 2012). The split-marker deletion constructs were generated by first amplifying two approximately 800-bp fragments: X-upstream and X-downstream, which corresponded to the approximately 800-bp region immediately upstream and downstream, respectively, of the coding region of the targeted gene. For each fragment, " $\mathrm{X}$ " refers to one or more $F U B$ gene designations, e.g., FUB5. The template for these PCR amplifications was genomic DNA from the wild-type strain of $F$. verticillioides. Next, two approximately 1,700-bp overlapping fragments, corresponding to the $5^{\prime}$ two thirds (Hyg-5') and $3^{\prime}$ two thirds (Hyg- $\left.3^{\prime}\right)$ of $H y g B$, were amplified from plasmid pHygAsc (Brown et al. 2002). Hyg-5' was amplified with primers M13FL and HY, while Hyg-3' was amplified with primers M13RL and YG. Amplicons X-upstream and Hyg-3' were then fused by PCR, using nested primers XFN and HYN. Likewise, amplicons Xdownstream and Hyg $-5^{\prime}$ were fused using nested primers XFN and YGN. Simultaneous deletion of FUB6, FUB7, FUB8, and FUB 9 was also accomplished by the split-marker method, by first generating amplicons Fub6-9A and Fub6-9B, which corresponded to the 800-bp region immediately downstream of the predicted coding region of $F U B 6$ and $F U B 9$, respectively. All primers are listed in Supplementary Table 1.

Replacement of one or more of the target genes with $\mathrm{HygB}$ occurred by integration of the X-upstream/Hyg- $3^{\prime}$ and X-downstream/Hyg- $5^{\prime}$ fusion amplicons into the genome via three homologous recombination events (Catlett et al. 2002). Following the protoplast transformation protocol, hygromycin-resistant transformants were selected by overlaying the regeneration medium with $1 \%$ water agar containing $300 \mu \mathrm{g}$ of hygromycin B per milliliter (Invitrogen, San Diego, CA, U.S.A.). Hygromycin-resistant transformants were subjected to three PCR analyses to determine whether targeted DNA had been deleted and replaced with $H y g B$ and whether the three predicted homologous recombination events had occurred. In the first PCR analysis, primers XLT and XRT, which were complementary to sequences just flanking the targeted gene, were expected to amplify a fragment corresponding to the coding region of the target gene from the wild type and a fragment corresponding to the $H y g B$ gene from deletion mutants. In the second PCR analysis, primers XLFN and Hygout1 were expected to amplify an approximately 900-bp fragment from deletion mutants but no fragment from the wild type (Supplementary Fig. 1). In the third PCR analysis, primers XRFN and Hygout2 were expected to amplify an approximately 900-bp fragment from deletion mutants but no fragment from the wild type. Transformants that yielded the pattern of PCR bands predicted for deletion of the target gene and its replacement with $H y g B$, referred to as $\triangle F_{v X}$ (e.g., $\left.\triangle F_{v} F U B 5\right)$, were regrown from a single conidium prior to further analysis.

Inactivation of genes in $F$. oxysporum was accomplished by deletion of target coding regions via the split-marker approach and protoplast transformation, as described above for $F$. verticillioides but with some notable differences. F. oxysporum split-marker constructs were generated by first amplifying two 1,000-bp fragments, one corresponding to the $5^{\prime}$ and the other to the $3^{\prime}$ flanking regions (flanks) of the coding region of the target gene. Fusion PCR, as described by $\mathrm{Yu}$ and associates (2004), was then used to fuse these fragments to either end of GenR. For fusion PCR, the PCR-amplified fragments $5^{\prime}$ flank, GenR, and $3^{\prime}$ flank were mixed at a molar ratio of $1: 3: 1$, respectively, under the following conditions: $95^{\circ} \mathrm{C}$ for $3 \mathrm{~min}$. followed by 10 cycles of $94^{\circ} \mathrm{C}$ for $30 \mathrm{~s}, 58^{\circ} \mathrm{C}$ for $10 \mathrm{~min}, 72^{\circ} \mathrm{C}$ for $5 \mathrm{~min}$, and a $10-\mathrm{min}$ extension at $72^{\circ} \mathrm{C}$. The resulting $5^{\prime}$ flank-GenR-3' flank fusion product was then used as a template in PCR to amplify split-marker fragments. Primers NF and gen-NR were used to amplify a split-marker fragment corresponding to the $5^{\prime}$ flank fused to the $5^{\prime}$ approximate twothirds of GenR, and primers NR and gen-NF were used to amplify a split-marker fragment corresponding to the $3^{\prime}$ approximate two-thirds of GenR fused to the $3^{\prime}$ flank. All PCR amplifications were performed using TaKaRa Ex Taq polymerase (TaKaRa Bio Inc., Shiga, Japan). Primers used in construction of split-marker fragments for $F$. oxysporum are listed in Supplementary Table 2. The GenR fragment used in fusion PCR was amplified from plasmid pII99 (Namiki et al. 2001) with primers gen-F and gen-R.

To generate $F$. oxysporum protoplasts, conidia were germinated overnight in YPG broth at $25^{\circ} \mathrm{C}$. The resulting mycelia were collected by filtration (Whatman filter paper), washed with $1 \mathrm{M} \mathrm{NH} \mathrm{NH}_{4} \mathrm{Cl}$ and were then incubated in a Driselase (Sigma-Aldrich, St. Louis) solution with $1 \mathrm{M} \mathrm{NH}_{4} \mathrm{Cl}$ (1.05 g to $70 \mathrm{ml}$ ) for 3 to $4 \mathrm{~h}$ at $30^{\circ} \mathrm{C}$ with agitation $(50 \mathrm{rpm})$. The incubation was allowed to proceed until $10^{6}$ protoplasts were formed per milliliter of solution. Protoplasts were harvested by centrifugation at 7,000 rpm for $5 \mathrm{~min}$ at $4^{\circ} \mathrm{C}$.

Replacement of the target gene with GenR occurred by integration of the NF/gen-NR and NR/gen-NF fusion amplicons into the genome via homologous recombination (Yu et al. 2004). Following the protoplast transformation protocol, geneticinresistant transformants were selected by overlaying the regeneration medium with $1 \%$ water agar containing $100 \mu \mathrm{g}$ of geneticin per milliliter (Invitrogen). Geneticin-resistant transformants were screened initially by PCR to identify those missing the target gene. Selected PCR-positive deletion mutants of FUB1, FUB3, FUB6, FUB8, and FUB10 were subjected to Southern analysis for verification. DNA probes for hybridization were labeled with $\left[{ }^{32} \mathrm{P}\right] \mathrm{dCTP}$, using the Amersham Rediprime II labeling system (GE Healthcare, Buckinghamshire, U.K.). The probes were synthesized by PCR from genomic DNA of the wild-type $F$. oxysporum Foxy20 strain with one set of the internal primers per gene.

\section{Mutant complementation.}

One each of the $F$. verticillioides fub4, fub5, fub10, and fub11 deletion mutants were complemented by transformation with vectors containing a wild-type copy of the target $F U B$ gene plus approximately $700 \mathrm{bp}$ upstream of the predicted start 
codon and approximately 300 bp downstream of the predicted stop codon. The vectors also included GenR as a selectable marker (Marek et al. 1989). For example, the fub4 complementation vector pFub4 was created by PCR amplification of a 1,794-bp fragment with primers Fub4AbF and Fub4AbR and wild-type $F$. verticillioides genomic DNA, followed by cloning the fragment into the pCR-XL-TOPO plasmid (Invitrogen). A fragment of DNA containing GenR was then cloned into the NotI restriction site present in the pCR-XL-TOPO element of pFub4. The resulting plasmid pFub4C was introduced into the genome of $f u b 4$ deletion mutant $\Delta \mathrm{FvFub} 4.9$ via protoplast-mediated transformation. Following the protoplast transformation protocol, geneticin-resistant transformants were selected by overlaying the regeneration medium with $1 \%$ water agar containing $300 \mu \mathrm{g}$ of geneticin per milliliter (Invitrogen). Geneticinresistant transformants were subjected to a PCR screen to determine whether they carried the complementation construct. The screen employed vector-specific primers 1840 and 1841 which, for $F U B 4, F U B 5, F U B 10$, and FUB11, amplify a DNA fragment larger than the targeted gene. Transformants that yielded the expected amplicon were reisolated from a single conidium and the resulting isolates were reanalyzed by PCR to confirm the presence of the complementation construct.

\section{qPCR.}

qPCR was carried out in $F$. verticillioides to examine differences in transcript levels for FUB1, FUB3, FUB8, and FUB10 in the wild-type strain, FUB10 mutants, and FUB10 complementation strains after $48 \mathrm{~h}$ of growth in GYAM. singlestranded (ss)DNA was generated from RNA isolated from harvested mycelia using the Quantitect RT kit (Qiagen, Venlo, Netherlands). PCR reactions were carried out using the RotorGene PCR machine (Qiagen), utilizing the Rotor-Gene SYBR Green kit (Qiagen) in $25 \mu \mathrm{l}$. Reaction conditions followed the manufactures recommendations: $95^{\circ} \mathrm{C}$ for $5 \mathrm{~min}$ to activate the polymerase, followed by 40 cycles of $95^{\circ} \mathrm{C}$ for $5 \mathrm{~s}$ and $60^{\circ} \mathrm{C}$ for $10 \mathrm{~s}$. A melting curve from 50 to $95^{\circ} \mathrm{C}$ with reads every $1^{\circ} \mathrm{C}$ was generated to ensure that individual amplicons were produced. Concentration of DNA measured in nanograms per microliter were determined by comparison to a standard curve generated for CYP2 (FVEG_00403, encoding a putative cyclophilin) and $U B C$ (FVEG_11477, encoding a putative ubiquitin conjugating enzyme) using primers 2193/2194 and 2195/2196, respectively. For the most part, means of three subsamples per flask were used so that three flasks per strain $\times$ time interaction were treated as the replication. Calculated concentrations (CALCONC) of transcripts of the same gene from the three F. verticillioides strains were analyzed by single-factor, mixed model analysis of variance (ANOVA) using a completely randomized design. Technical and biological replicates were combined. Levene's homogeneity of variance tests of all datasets indicated that transformation of data for FUB1, FUB3, and FUB8 was required to stabilize variance for ANOVA; the transformations were $\operatorname{Ln}\{($ CALCONC-0.09)/21250 $\}, \operatorname{Ln}\{($ CALCONC-0.009)/ $16350\}$, and $\operatorname{Ln}(\mathrm{CALCONC} / 12655)$ for $F U B 1, F U B 3$, and $F U B 8$, respectively. ANOVA tests were conducted on transformed data when necessary but untransformed means are presented for ease of interpretation. When ANOVA indicated a significant $(P \leq 0.05)$ F-test value, a least squares means analysis was used to determine which treatments differed from one another. SAS 9.2 software (SAS Institute Inc. Cary, NC, U.S.A) was used for the statistical analyses.

qPCR was carried out with $F$. verticillioides genomic DNA to examine relative difference of the $F U B 10$ coding DNA in the FUB10 complementation strain $\triangle$ FvFub10.5AB815 as compared with the wild-type. PCR reactions were carried out essentially as described above, except that approximately 2.5 ng of genomic DNA from each strain were used as template. Average threshold cycle $(\mathrm{Ct})$ values were generated from three subsamples per genomic DNA. The calculated relative fold difference of the FUB10 amplicon in complementation strain DNA as compared with wild-type DNA was normalized to the geometric mean of the two unmanipulated endogenous controls, FUB8 and CYPl (FVEG_07816, encoding a Trm112like protein; primers 2203 and 2204).

qPCR was carried out in $F$. oxysporum to examine differences in transcript levels for 17 genes in the wild-type and FUB10 deletion mutant after growth on $\mathrm{CDB}$, which induces FA production in $F$. oxysporum, and minimal medium, which does not induce FA production. Integrated DNA Technologies PrimerQuest software was used to design gene-specific PCR primers. Translation elongation factor 1 alpha $(E F 1 \alpha$, FOXG_03515) served as an endogenous control. Total RNA was extracted from harvested mycelia using the RNA extraction kit (iNtRON Biotechnology, Daejeon, Korea) according to the manufacturer's protocol. ssDNA was generated from RNA using the SuperScript III first-strand synthesis system (Invitrogen) as described previously (Lee et al. 2014). PCR reactions were performed in an iCycler iQ5 real time PCR detection system (Bio-Rad, Hercules, CA, U.S.A.). The PCR thermal cycling conditions were as follows: $95^{\circ} \mathrm{C}$ for $3 \mathrm{~min}$, followed by 45 cycles at $95^{\circ} \mathrm{C}$ for $10 \mathrm{~s}, 60^{\circ} \mathrm{C}$ for $20 \mathrm{~s}, 72^{\circ} \mathrm{C}$ for $20 \mathrm{~s}$. The PCR reaction contained $10 \mu \mathrm{l}$ of $2 \times$ iQ SYBR green supermix (Bio-Rad), $0.5 \mu \mathrm{l}$ of each primer $(10 \mathrm{pM}), 1 \mu \mathrm{l}$ of template cDNA (12.5 ng), and water to a final volume of $20 \mu \mathrm{l}$. Quantification values were automatically determined using the BioRad CFX Manager version 1.6 and the $\mathrm{Ct}$ values were determined. In all experiments, negative control reactions containing no template DNA were subjected to the same procedure to detect DNA contamination. This experiment was done two times. In each experiment, three technical replicates were done for each treatment, and final $\mathrm{Ct}$ values are presented as the average of the replicates. $\mathrm{Ct}$ values were normalized with the $\mathrm{Ct}$ value of EFI $\alpha$ and the normalized levels of each gene were compared with the level of the wild type on day 3 in MM.

\section{Analysis of FA.}

Ten-day-old cracked maize kernel cultures of $F$. verticillioides and culture filtrates from 21-day-old CDB cultures of $F$. oxysporum were extracted with acetonitrile/water $(50 \%$ vol/vol) acidified to $\mathrm{pH} 2$ with $\mathrm{HCl}$. FA concentrations in $F$. verticillioides extracts were determined by HPLC coupled to a tandem mass spectrometer in a manner similar to that previously described (Brown et al. 2012). The LC-MS/MS apparatus included a DIONEX (ThermoFisher Scientific, Waltham, MA, U.S.A.) Ultimate 3000 HPLC coupled to a SCIEX (AB SCIEX, Framingham, MA, U.S.A.) QTRAP 3200. Briefly, 10 $\mu \mathrm{l}$ of extract was injected into an $800 \mu \mathrm{l} / \mathrm{min}$ gradient flow of water (solvent A) and acetonitrile (solvent B) through an XBridge (Waters, Milford, MA, U.S.A.) C18 chromatography column (4.6 mm diameter $\times 150 \mathrm{~mm}$ length, $3.5 \mu \mathrm{m}$ particle size). Solvents included $0.5 \%$ formic acid. A solvent program (0 min: 10\% B, 1 min: $10 \%$ B, 8.5 min: $90 \%$ B, 10 min: $90 \%$ B, 12 min: $10 \%$ B, 13 min: $10 \%$ B) was used to effectively elute the FA for MS/MS detection. Approximately $10 \%$ of the LC eluent was directed to the electrospray ionization (ESI) source of the MS, while the remainder was directed to a waste container. Parameters for the MS/MS detection of the FA were empirically optimized to maximize sensitive detection. The ESI source was operated in positive mode at a voltage of 5,500 $\mathrm{V}$ and the collision energy for stimulation of ion fragmentation was set to 10 . The MS was operated in multiple reaction monitoring mode to observe several distinctive ions produced upon fragmentation of the protonated $[\mathrm{M}+\mathrm{H}]^{+} \mathrm{FA}$ ion. The parent 
ion $(m / z, 180)$ and fragment ions $(m / z, 134,152,162)$ were monitored and quantitation was based upon integrated intensity of the $m / z, 134$ ion. Operation of the LC-MS/MS instrument and interpretation of the acquired data were done utilizing the Analyst software provided by the MS instrument manufacturer.

F. oxysporum extracts were analyzed with an HPLC (Agilent 1100, Agilent Technologies, Waldbronn, Germany) equipped with the diode-array detector set at $254 \mathrm{~nm}$ and Zobax C18 column $\left(4.6 \times 150 \mathrm{~mm}, 40^{\circ} \mathrm{C}\right)$. The mobile phase was acetonitrile and water containing $0.5 \%$ trifluoroacetic acid. The flow rate was $1.0 \mathrm{ml} / \mathrm{min}$ and the injection volume was $25 \mu \mathrm{l}$. The FA standard was purchased from Sigma-Aldrich.

\section{Pathogenicity assays.}

Pathogenicity of $F$. oxysporum and phytotoxicity of its culture filtrates were assessed with a cactus shoot assay, using the three-angled cactus Hylocereus trigonus, because the wildtype progenitor strain Foxy20 was originally isolated from cactus. Shoots of plants grown in the greenhouse for one year were cut into $0.5-\mathrm{cm}$-thick cross sections and were then placed on moistened Whatman No. 2 filter papers in an $8-\mathrm{cm}$ petri dish. The central portion of each cross section was treated in one of the following ways: i) a 4-mm diameter block was excised from PDA cultures of $F$. oxysporum grown at $25^{\circ} \mathrm{C}$ for 7 days, ii) $0.1 \mathrm{ml}$ of a suspension of $10^{4}$ or $10^{6} \mathrm{~F}$. oxysporum conidia per milliliter, or iii) $0.1 \mathrm{ml}$ of culture filtrate prepared by passing a 21-day-old CDB culture of $F$. oxysporum through a $0.2 \mu \mathrm{m}$ filter. Each treatment was applied to three cross sections per dish with three replications. Symptom development was examined after 4 days of incubation at $25^{\circ} \mathrm{C}$. Severity was assessed using a rating scale from 0 to 5 based on the percentage of tissue with visual symptoms in which $0=$ no reaction, $1=$ yellow or brown surface discoloration of the central portion of the cross section, 2 = central portion rotten and darkly discolored, $3=$ central portion rotten but rot is less than $3 \mathrm{~mm}$ deep, $4=$ central portion rotten more than $3 \mathrm{~mm}$ deep, $5=$ whole cross section rotted (Choi et al. 2010). The experiment was repeated with essentially identical results.

Pathogenicity of $F$. verticillioides was assessed with a seedling assay using the hybrid white sweet corn Silver Queen (Johnny's Selected Seed) (Glenn et al. 2008; Larson et al. 2011). Fungicide-free seeds were surface-sterilized by soaking in $100 \%$ commercial bleach $(6.25 \%$ sodium hypochlorite) for $10 \mathrm{~min}$, were rinsed with sterile water four times, were allowed to soak for $4 \mathrm{~h}$ in sterile water, and were then heat-shocked at $60^{\circ} \mathrm{C}$ for $5 \mathrm{~min}$. Thirty seeds were then incubated at $27^{\circ} \mathrm{C}$ overnight in $10 \mathrm{ml}$ of water containing $1 \times 10^{6} \mathrm{~F}$. verticillioides conidia per milliliter. Ten seeds were planted in $10-\mathrm{cm}$ plastic pots containing growing mix (Sunshine Redi-earth, Bellevue, WA, U.S.A.) that was sterilized twice in an autoclave at $121^{\circ} \mathrm{C}$ for 20 minutes. Pots were placed in a growth chamber with the following conditions: $14 \mathrm{~h}$ of light at $30^{\circ} \mathrm{C}$ and $10 \mathrm{~h}$ of dark at $20^{\circ} \mathrm{C}$. Disease symptoms were assessed after 16 days by counting the number of plants and measuring plant height.

\section{ACKNOWLEDGMENTS}

We thank C. McGovern, C. Probyn, and M. Moore for technical assistance and D. Palmquist for assistance with the statistical analysis. Part of the study was supported by the "Research Program for Agricultural Science \& Technology Development (Project No. PJ008432 and PJ008635)" and a grant from the "Next-Generation Bio Green21 Program (No. PJ008210)", National Academy of Agricultural Science, Rural Development Administration, Republic of Korea. Mention of trade names or commercial products in this article is solely for the purpose of providing specific information and does not imply recommendation or endorsement by the United States Department of Agriculture (USDA). USDA is an equal opportunity provider and employer.

\section{LITERATURE CITED}

Altschul, S. F., Madden, T. L., Schaffer, A. A., Zhang, J., Zhang, Z., Miller, W., and Lipman, D. J. 1997. Gapped BLAST and PSI-BLAST: A new generation of protein database search programs. Nucleic Acids Res. 25:3389-3402.

Bacon, C. W., Porter, J. K., Norred, W. P., and Leslie, J. F. 1996. Production of fusaric acid by Fusarium species. Appl. Environ. Microbiol. 62:4039-4043.

Baker, S. E., Perrone, G., Richardson, N. M., Gallo, A., and Kubicek, C. P. 2012. Phylogenomic analysis of polyketide synthase-encoding genes in Trichoderma. Microbiology. 158:147-154.

Bolstad, B. M., Irizarry, R. A., Astrand, M., and Speed, T. P. 2003. A comparison of normalization methods for high density oligonucleotide array data based on variance and bias. Bioinformatics. 19:185-193.

Boonman, N., Prachya, S., Boonmee, A., Kittakoop, P., Wiyakrutta, S., Sriubolmas, N., Warit, S., and Dharmkrong-At Chusattayanond, A. 2012. In vitro acanthamoebicidal activity of fusaric acid and dehydrofusaric acid from an endophytic fungus Fusarium sp. Tlau3. Planta Med. 78:1562-1567.

Bouizgarne, B., El-Maarouf-Bouteau, H., Madiona, K., Biligui, B., Monestiez, M., Pennarun, A. M., Amiar, Z., Rona, J. P., Ouhdouch, Y., El Hadrami, I., and Bouteau, F. 2006. A putative role for fusaric acid in biocontrol of the parasitic angiosperm Orobanche ramosa. Mol. PlantMicrobe Interact. 19:550-556.

Brown, D. W., McCormick, S. P., Alexander, N. J., Proctor, R. H., and Desjardins, A. E. 2002. Inactivation of a cytochrome P-450 is a determinant of trichothecene diversity in Fusarium species. Fungal Genet. Biol. 36:224-233.

Brown, D. W., Cheung, F., Proctor, R. H., Butchko, R. A., Zheng, L., Lee, Y. Utterback, T., Smith, S., Feldblyum, T., Glenn, A. E., Plattner, R. D., Kendra, D. F., Town, C. D., and Whitelaw, C. A. 2005. Comparative analysis of 87,000 expressed sequence tags from the fumonisin-producing fungus Fusarium verticillioides. Fungal Genet. Biol. 42:848-861.

Brown, D. W., Butchko, R. A., Busman, M., and Proctor, R. H. 2012. Identification of gene clusters associated with fusaric acid, fusarin, and perithecial pigment production in Fusarium verticillioides. Fungal Genet. Biol. 49:521-532.

Catlett, N. L., Lee, B. N., Yoder, O. C., and Turgeon, B. G. 2002. Splitmarker recombination for efficient targeted deletion of fungal genes. Fun. Genet. News. 49:9-11.

Choi, M. O., Kim, S. G., and Kim, Y. H. 2010. Suppression of bipolaris stem rot on cactus by heat-inactivated conidial suspension of Bipolaris cactivora. Plant Pathol. J. 26:231-237.

D'Alton, A., and Etherton, B. 1984. Effects of fusaric acid on tomato root hair membrane potentials and ATP levels. Plant Physiol. 74:39-42.

Desjardins, A. E. 2006. Fusarium mycotoxins chemistry, genetics and biology. APS Press, St. Paul, MN, U.S.A.

Dyer, R. B., Plattner, R. D., Kendra, D. F., and Brown, D. W. 2005 Fusarium graminearum TRI14 is required for high virulence and DON production on wheat but not for DON synthesis in vitro. J. Agric. Food Chem. 53:9281-9287.

Glenn, A. E., Zitomer, N. C., Zimeri, A. M., Williams, L. D., Riley, R. T., and Proctor, R. H. 2008. Transformation-mediated complementation of a FUM gene cluster deletion in Fusarium verticillioides restores both fumonisin production and pathogenicity on maize seedlings. Mol. Plant-Microbe Interact. 21:87-97.

Irizarry, R. A., Hobbs, B., Collin, F., Beazer-Barclay, Y. D., Antonellis, K. J., Scherf, U., and Speed, T. P. 2003. Exploration, normalization, and summaries of high density oligonucleotide array probe level data. Biostatistics. 4:249-264.

Jiao, J., Zhou, B., Zhu, X., Gao, Z., and Liang, Y. 2013. Fusaric acid induction of programmed cell death modulated through nitric oxide signalling in tobacco suspension cells. Planta. 238:727-737.

Keller, N. P., Turner, G., and Bennett, J. W. 2005. Fungal secondary metabolism-From biochemistry to genomics. Nat. Rev. Microbiol. 3:937947.

Larson, T. M., Kendra, D. F., Busman, M., and Brown, D. W. 2011. Fusarium verticillioides chitin synthases $C H S 5$ and $C H S 7$ are required for normal growth and pathogenicity. Curr. Genet. 57:177-189.

Lee, T., Shin, J. Y., Son, S. W., Lee, S., and Ryu, J.-G. 2013. Fusaric acid production in Fusarium oxysporum transformants generated by restriction enzyme-mediated integration (REMI) procedure. Res. Plant Dis. 19:254-258.

Lee, T., Lee, S.-H., Shin, J. Y., Kim, H.-K., Yun, S.-H., Kim, H.-Y., Lee, S., and Ryu, J.-G. 2014. Comparison of trichothecene biosynthetic gene expression between Fusarium graminearum and Fusarium asiaticum. Plant Pathol. J. 30:33-42.

Leslie, J. F., and Summerell, B. A. 2006. The Fusarium laboratory manual. Blackwell Publishing, Ames, IA, U.S.A. 
Leslie, J. F., Plattner, R. D., Desjardins, A. E., and Klittich, C. J. R. 1992 Fumonisin $\mathrm{B}_{1}$ production by strains from different mating populations of Gibberella fujikuroi (Fusarium section Liseola). Phytopathology. 82:341-345.

Li, C., Zuo, C., Deng, G., Kuang, R., Yang, Q., Hu, C., Sheng, O., Zhang, S., Ma, L., Wei, Y., Yang, J., Liu, S., Biswas, M. K., Viljoen, A., and Yi, G. 2013. Contamination of bananas with beauvericin and fusaric acid produced by Fusarium oxysporum f. sp. cubense. PLoS One. 8:e70226. Published online.

Marek, E. T., Schardl, C. L., and Smith, D. A. 1989. Molecular transformation of Fusarium solani with an antibiotic resistance marker having no fungal DNA homology. Curr. Genet. 15:421-428.

Namiki, F., Matsunaga, M., Okuda, M., Inoue, I., Nishi, K., Fujita, Y., and Tsuge, T. 2001. Mutation of an arginine biosynthesis gene causes reduced pathogenicity in Fusarium oxysporum f. sp. melonis. Mol. PlantMicrobe Interact. 14:580-584.

Niehaus, E. M., von Bargen, K. W., Espino, J. J., Pfannmuller, A., Humpf, H. U., and Tudzynski, B. 2014. Characterization of the fusaric acid gene cluster in Fusarium fujikuroi. Appl. Microbiol. Biotechnol. 98:1749-1762.

O’Donnell, K., Rooney, A. P., Proctor, R. H., Brown, D. W., McCormick, S. P., Ward, T. J., Frandsen, R. J., Lysoe, E., Rehner, S. A., Aoki, T., Robert, V. A., Crous, P. W., Groenewald, J. Z., Kang, S., and Geiser, D. M. 2013. Phylogenetic analyses of RPB1 and RPB2 support a middle Cretaceous origin for a clade comprising all agriculturally and medically important fusaria. Fungal Genet. Biol. 52:20-31.

Osbourn, A. 2010. Secondary metabolic gene clusters: Evolutionary toolkits for chemical innovation. Trends Genet. 26:449-457.

Pan, J. H., Chen, Y., Huang, Y. H., Tao, Y. W., Wang, J., Li, Y., Peng, Y., Dong, T., Lai, X. M., and Lin, Y. C. 2011. Antimycobacterial activity of fusaric acid from a mangrove endophyte and its metal complexes. Arch. Pharm. Res. 34:1177-1181.

Proctor, R. H., Desjardins, A. E., Plattner, R. D., and Hohn, T. M. 1999. A polyketide synthase gene required for biosynthesis of fumonisin mycotoxins in Gibberella fujikuroi mating population A. Fungal Genet. Biol. 27:100-112.

Proctor, R. H., McCormick, S. P., Alexander, N. J., and Desjardins, A. E. 2009. Evidence that a secondary metabolic biosynthetic gene cluster has grown by gene relocation during evolution of the filamentous fungus Fusarium. Mol. Microbiol. 74:1128-1142.

Samadi, L., and Behboodi, B. S. 2006. Fusaric acid induces apoptosis in saffron root-tip cells: Roles of caspase-like activity, cytochrome $c$, and $\mathrm{H}_{2} \mathrm{O}_{2}$. Planta. 225:223-234

Sambrook, J., Fritsch, E. F., and Maniatis, T. 2001. Molecular Cloning: A Laboratory Manual. Cold Spring Harbor Laboratory, Cold Spring Harbor, NY, U.S.A.
Son, S. W., Kim, H. Y., Choi, G. J., Lim, H. K., Jang, K. S., Lee, S. O, Lee, S., Sung, N. D., and Kim, J. C. 2008. Bikaverin and fusaric acid from Fusarium oxysporum show antioomycete activity against Phytophthora infestans. J. Appl. Microbiol. 104:692-698.

Stipanovic, R. D., Puckhaber, L. S., Liu, J., and Bell, A. A. 2011a. Phytotoxicity of fusaric acid and analogs to cotton. Toxicon. 57:176-178.

Stipanovic, R. D., Wheeler, M. H., Puckhaber, L. S., Liu, J., Bell, A. A., Williams, H. J. 2011b. Nuclear Magnetic Resonance (NMR) studies on the biosynthesis of fusaric acid from Fusarium oxysporum f. sp. vasinfectum. J. Agric. Food Chem. 59:5351-5356.

Tuite, J. 1969. Plant Pathological Methods: Fungi and Bacteria. Burgess Publishing Company, Minneapolis.

Vesonder, R. F., and Golinksi, P. 1989. Metabolites of Fusarium. Page 492 in: Fusarium. Mycotoxins, taxonomy and pathogenicity. J. Chełkowski, ed. Elsevier, Amsterdam.

Wiemann, P., Sieber, C. M., von Bargen, K. W., Studt, L., Niehaus, E. M., Espino, J. J., Huss, K., Michielse, C. B., Albermann, S., Wagner, D. Bergner, S. V., Connolly, L. R., Fischer, A., Reuter, G., Kleigrewe, K., Bald, T., Wingfield, B. D., Ophir, R., Freeman, S., Hippler, M., Smith, K. M., Brown, D. W., Proctor, R. H., Munsterkotter, M., Freitag, M. Humpf, H. U., Guldener, U., and Tudzynski, B. 2013. Deciphering the cryptic genome: Genome-wide analyses of the rice pathogen Fusarium fujikuroi reveal complex regulation of secondary metabolism and novel metabolites. PLoS Pathog. 9:e1003475.

Young, C. A., Felitti, S., Shields, K., Spangenberg, G., Johnson, R. D. Bryan, G. T., Saikia, S., and Scott, B. 2006. A complex gene cluster for indole-diterpene biosynthesis in the grass endophyte Neotyphodium lolii. Fungal Genet. Biol. 43:679-693.

Yu, J. 2012. Current understanding on aflatoxin biosynthesis and future perspective in reducing aflatoxin contamination. Toxins. 4:1024-1057.

Yu, J. H., Hamari, Z., Han, K. H., Seo, J. A., Reyes-Dominguez, Y., and Scazzocchio, C. 2004. Double-joint PCR: A PCR-based molecular tool for gene manipulations in filamentous fungi. Fungal Genet. Biol. 41:973-981.

\section{AUTHOR RECOMMENDED INTERNET RESOURCES}

Broad Institute Fusarium Comparative database: www.broadinstitute.org/annotation/genome/fusarium_group/MultiHome. html

Gene Expression Omnibus: www.ncbi.nlm.nih.gov/geo

Institute of Bioinformatics and Systems Biology (IBIS) website: www.helmholtz-muenchen.de/en/ibis

Joint Genome Institute (JGI) Trichoderma atroviride database: genome.jgi-psf.org/Triat2/Triat2.home.html 